\title{
THE ROLE OF MULTIMEDIA IN ENHANCING ACHIEVEMENT MOTIVATION IN MATHEMATICS: A CASE STUDY ON THE SEVENTH GRADE STUDENTS IN NORTH EASTERN PROVINCE, SULTANATE OF OMAN

\author{
دور الوسائط المتعددة في تعزيز دافعية الإنجاز في الرياضيات: دراسة حالئة

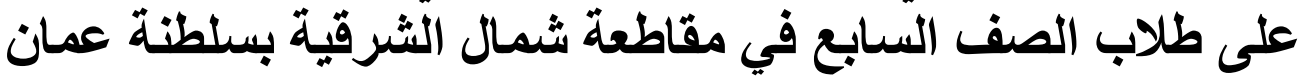

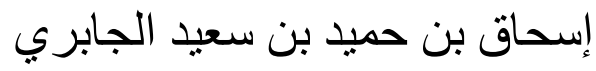

Isehaq Humaid Said Humaid Al Jabri ${ }^{1 \star}$ and Muhammad Sabri Sahrir ${ }^{2}$

${ }^{1}$ Ph.D. Candidate (Education) at the Faculty of Education (IIUM); aass123gg@gmail.com

${ }^{2}$ Prof. Dr. at the Faculty of Education (IIUM); muhdsabri@iium.edu.my International Islamic University Malaysia

${ }^{*}$ Corresponding Author

\begin{abstract}
This quantitative, analytical study discusses the impact of multimedia on enhancing motivation among seventh graders in the Northeastern District. Where the problem arose in the fact that research and studies indicated the low level of performance of seventh-graders in the mathematics lesson, and that the teaching method used is dominated by speech and instruction by the teachers, memorization by the students, without improving the level of his higher thinking capabilities and motivations in studying Maths. Therefore, the study aims to discuss the effect of multimedia on enhancing motivation among seventh-graders, and to know the statistically significant differences at the level of significance $(0.05)$ between the mean scores of the pre and post measurements of students of the experimental group that studied according to the multimedia program on the motivation scale for achievement in mathematics. Find out the teachers' suggestions on developing the multimedia program. The researcher used the descriptive approach and the semi-experimental approach to a sample of (153) mathematics students, that was divided into a control group (77) students, and an experimental group (76) students. The study tools included; the achievement test in the skills of solving the pre and post mathematical problems of the control and experimental group, the motivation scale in mathematics consisting of (33) paragraphs. The findings revealed that the multimedia program affects improving achievement motivation among students by $(13.1 \%)$ of achievement level for the experimental group, and that there are statistically significant differences at the significance level $(0.05)$ between the average achievement of the experimental group students, and the average achievement of the control group students in The level of motivation for achievement in mathematics subject, and the differences were in favor of the experimental group students sample
\end{abstract}

Keywords: Multimedia, Motivation, Mathematics. 


\section{الملخص}

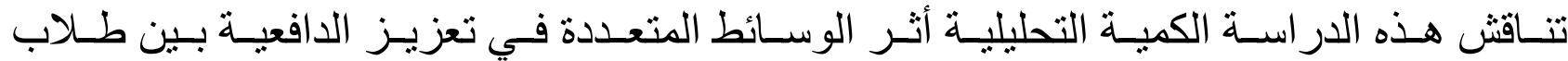

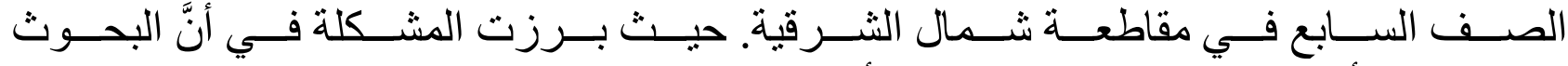

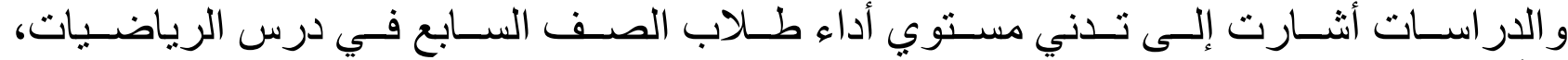

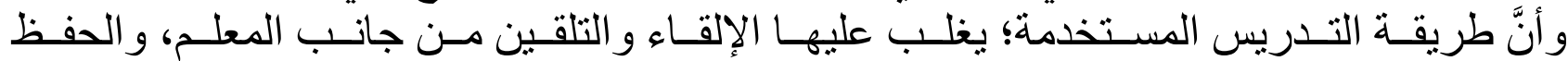

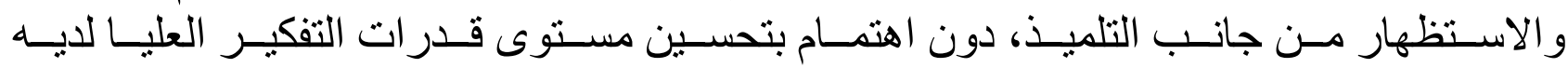
وتحفيـز الـدو افع في در اسـة الرياضـيات. لـذا تهـدف الدراسـة مناقثـة تـأثير الوســائط المتعـددة

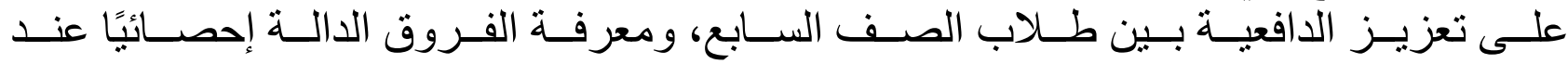

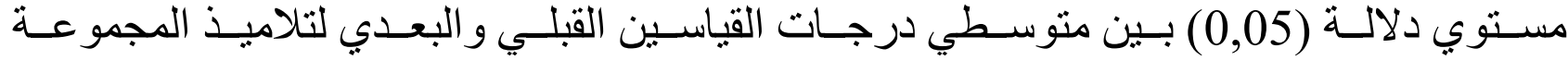

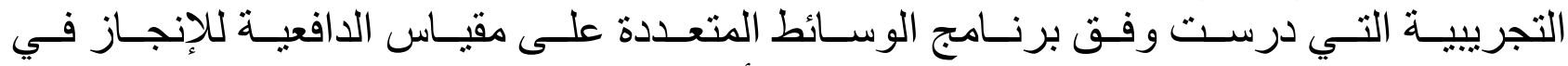

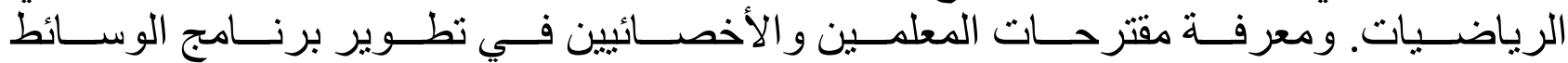

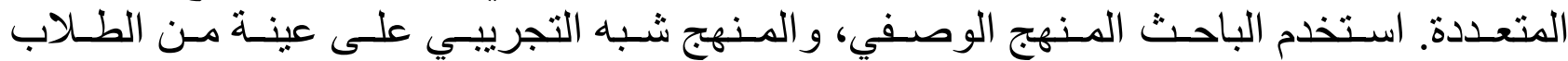

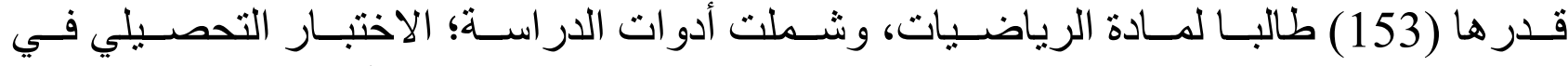

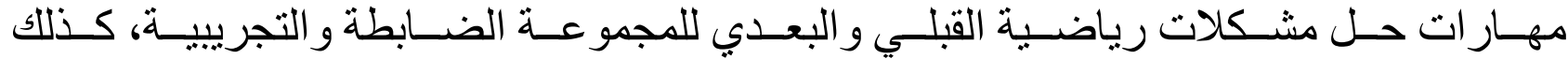

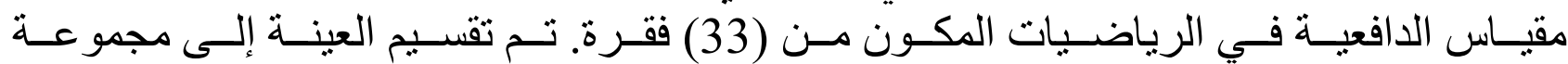

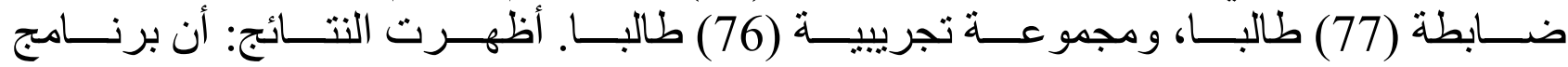

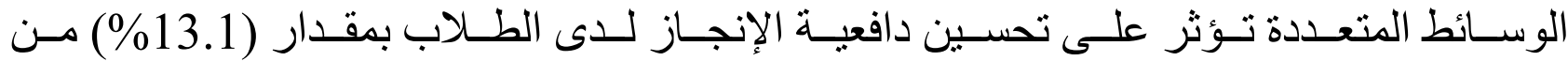

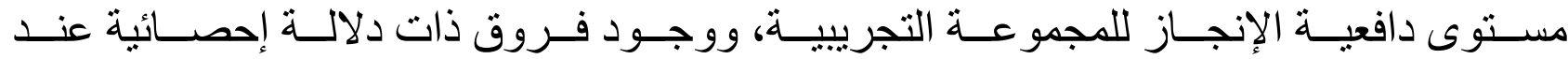

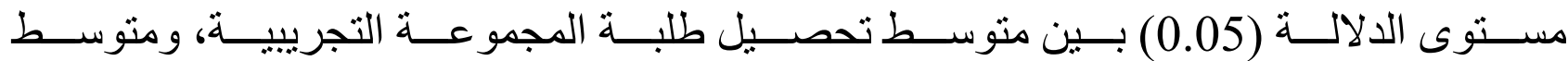

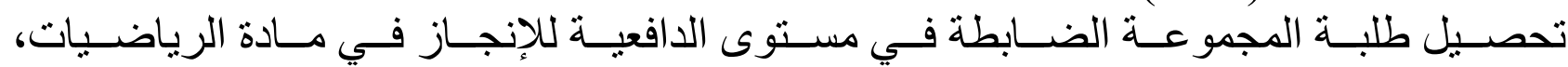

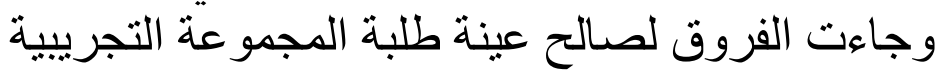
كلمات مفتاحية: الوسائط المتعددة، الدافعية، الرباضيات.

المقدمة:

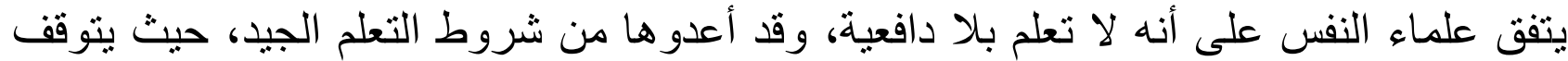

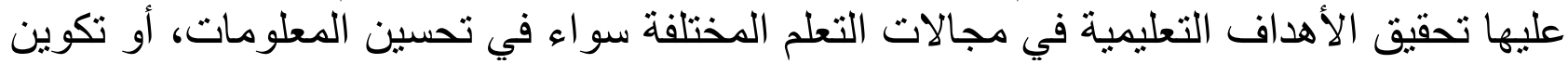

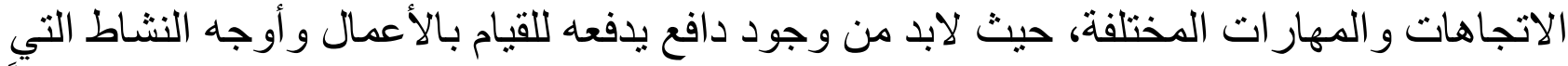
يتطلبها التعلم، و التغلب على العقبات التي يواجهات التها في مواقف التعلم، وكيف يتصرف فع معها تصرفاً سليماً تحقق لله تعلماً أفضل (سامي ملحم، 2006، 144). و عليه فإن دافعية الإنجاز لها وظيفة وفية مهمة أثناء تعلم الرياضيات حيث إنها تعمل على تنشيط الطلبة لممارسة الأنشطة المختلفة لتحقيق التعلم، كما تعمل على استثارة جهود الطلاب و المحافظة على طاقتهم لحين الانتهاء من الأنشطة و المهام الرياضية، كما أن لها أهمية ودور مساعد للطلاب في صياغة أهدافهم، وتساعدهم على أهى مو اجهة الصعوبات و التغلب عليها أثناء تعلم الرياضيات، وتزيد من مستوى الطموح و والثقة لديهم بشكل بتم من خلاله تحقيق ذو اتهم. 
ويرى النجدي، (2015: 155) أننا عند استشر اف المستقبل في القرن الحادي و العشرين نحتاج

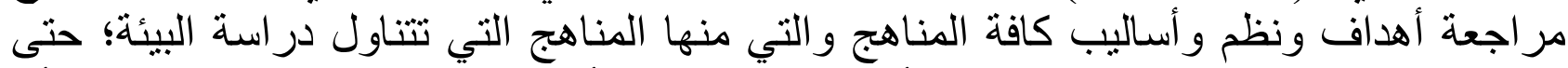

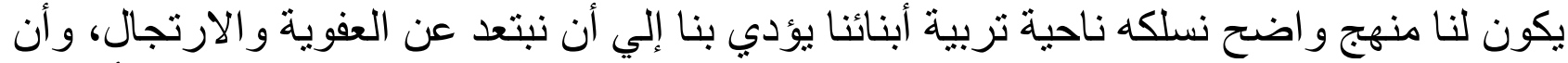

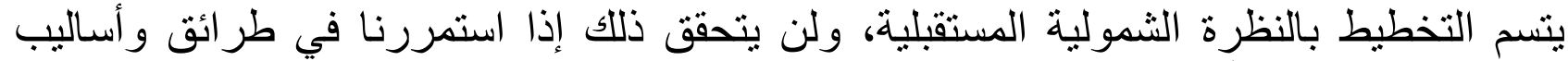

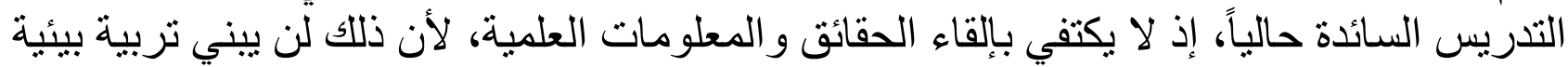

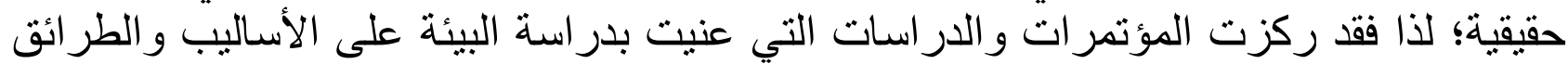

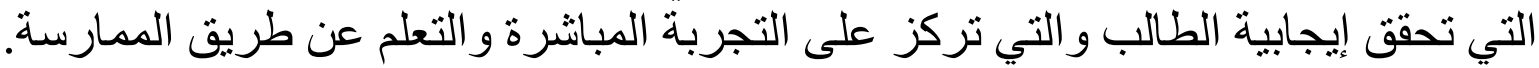
وتعتبر الوسائط التعليمية المتعددة والمتطورة من أكثر العبارات التي حظيت مؤخرًا باهتمام

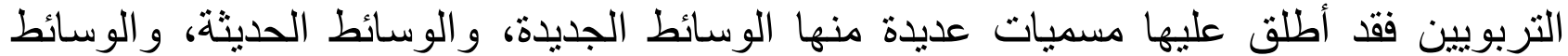

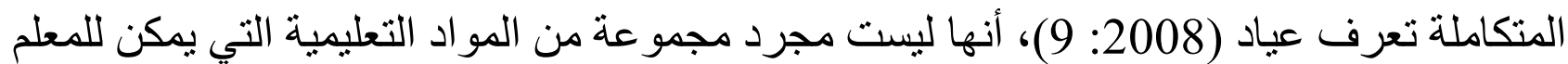

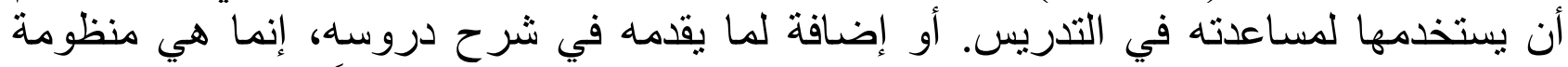

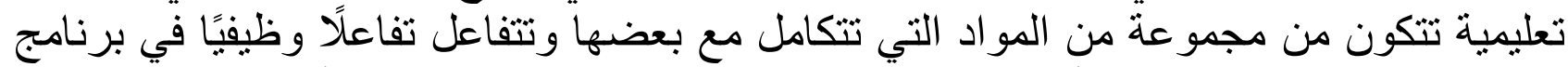

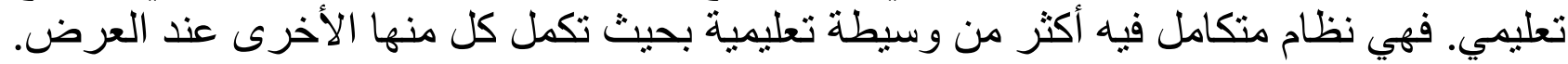

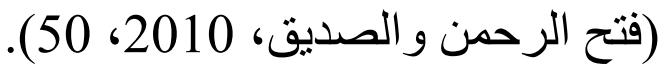

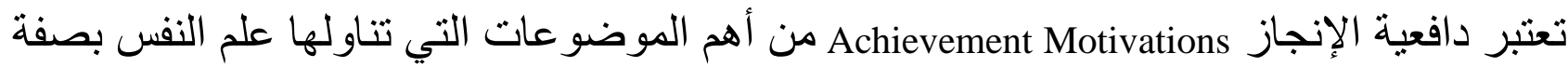

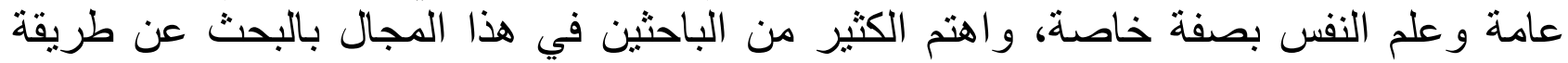

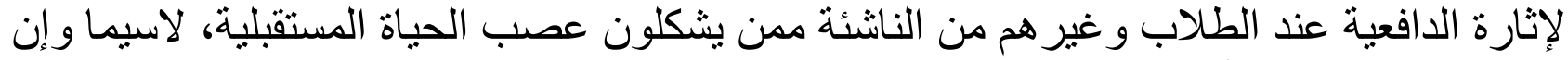

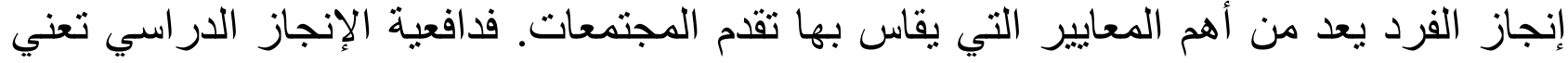

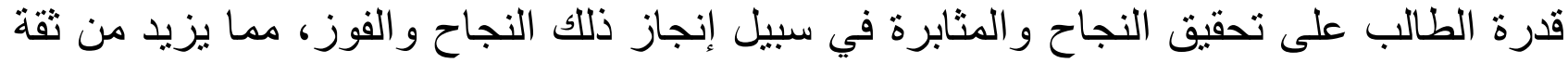

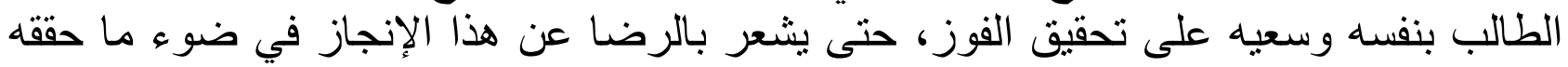

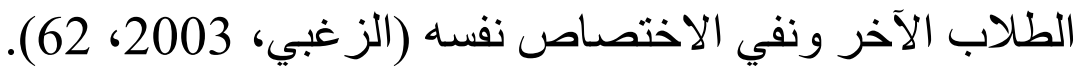

وتعرف الدافعية للإنجاز (Achievement Motivation) بأنها: "قدرة الفرد على اختيار أهداف و اقعية

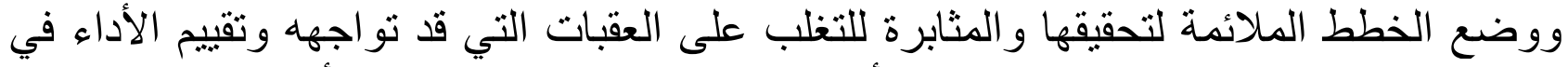

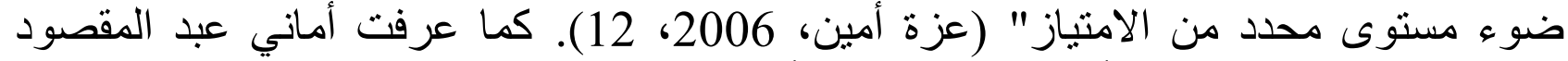

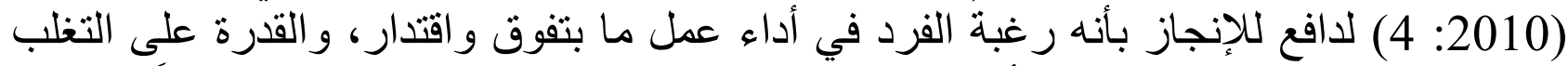

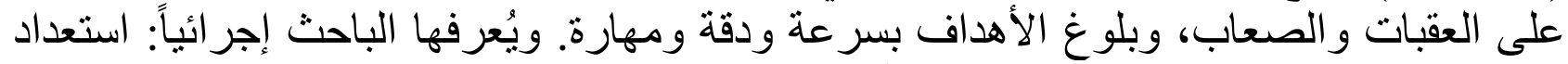

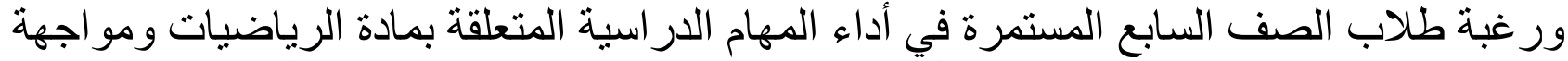

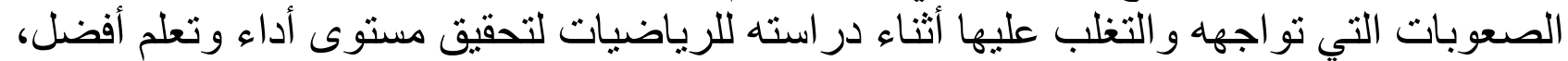

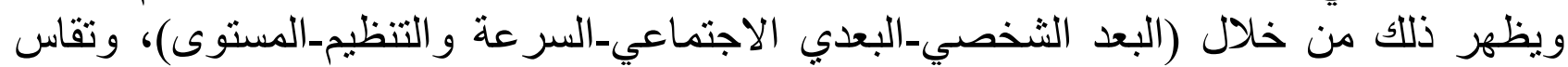

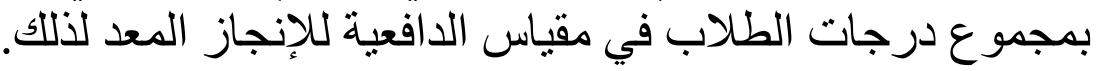

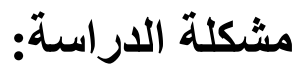

من خلال مر اجعة البحوث والدراسات في مجال تدريس الرياضيات، وجد الباحث أنها تؤكد في في الرئي

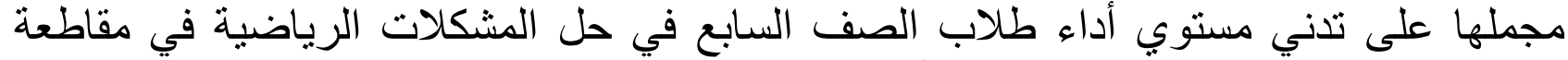

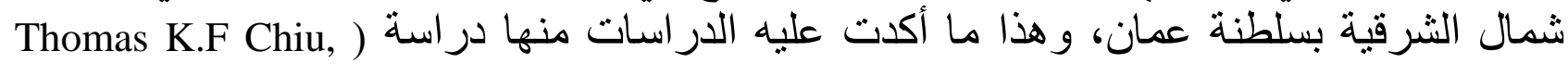

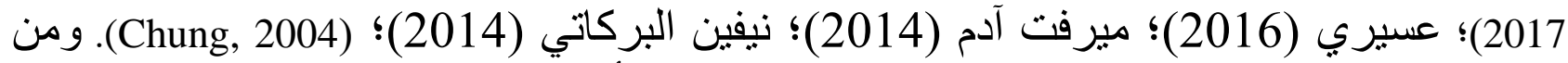
خلال حضوره بعض حصص الرياضيات، وجد الباحث أن طريقة التدريس المستخدمة؛ يغلب 
عليها الإلقاء و التلقين من جانب المعلم، و الحفظ والاستظهار من جانب التلمبذ، دون اهتمام بتحسين مستوى قدر ات التفكير العليا لديه ومنها القدرة على حل المشكلات الرياضية. وهذا ما ذكر أيضاً في در اسة خليفة (2008) حين أشار إلى الأساليب التقليدية في تدريس الرياضيات. ومن أهم الأسباب التي دفعت الباحث للبحث في هذه المشكلة؛ هو تدني مستوى الطلاب في اختبار ات تميس (2015) TIMSS التي ظهر فيها مستوى السلطنة دون المتوسط كما أوضحت هده النتائج. وبعد التحليل الاختبار من قبل الوزارة ظهر أن أضعف الجوانب تمثل في تدني مسائل حل المشكلات.

وللتأكيد على المشكلة، تم مراجعة نتائج طلاب الصف السابع للعام الدراسي (2018 - 2019) لاى قسم الإحصاء بالمدرية العامة للتربية و التعليم بشمال الثرقية، وكانت النتائج تدني متوسط

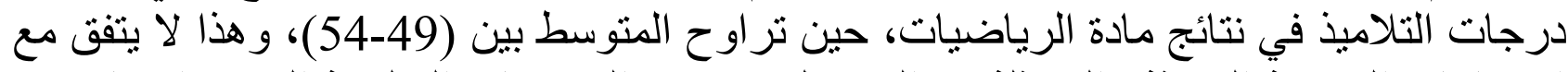
الاتجاهات التربوية الحديثة و المتمنلة في الوصول بمستوى المنتوجات التعليمية إلى حد الإتقان.

أهداف الدر اسةة:

أ. مناقثــة دور الوسـائط المتعـددة فـي تحسـين الدافعيـة للإنجــاز في الرياضـيات لـدى طـلاب الصف السابع في مقاطعة شمال الثرقية بسلطنة عمان.

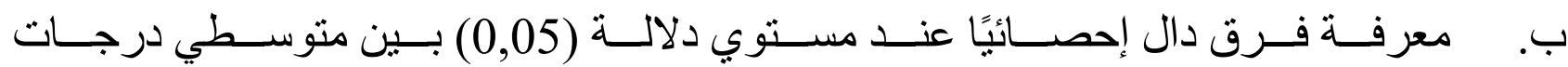

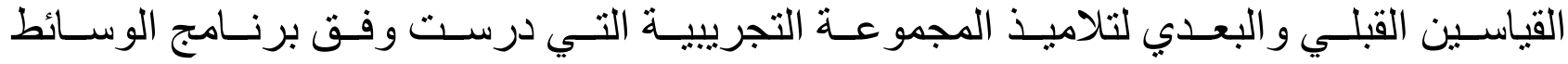
المتعددة على مقياس الدافعية للإنجاز في الرياضيات.

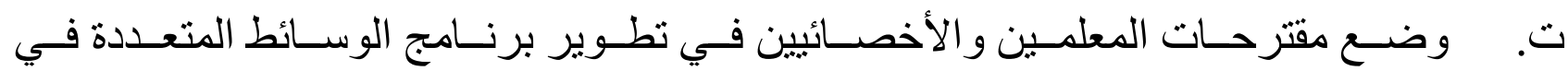
الرياضيات لاى طلاب الصف السابع في مقاطعة شمال الثرقية بسلطنة عمان. الار اسات السابقة:

مـن الدر اسـات التـي تتاولت دافعيـة الإنجـاز في الرياضـيات در اسـة ميرفـت آدم(2017) و التـي

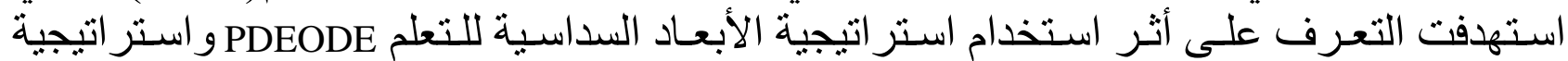

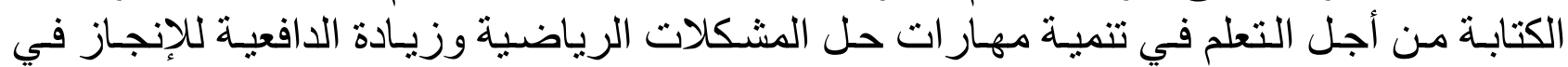

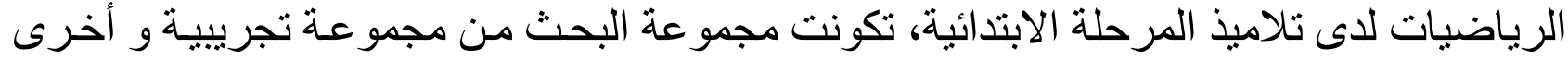

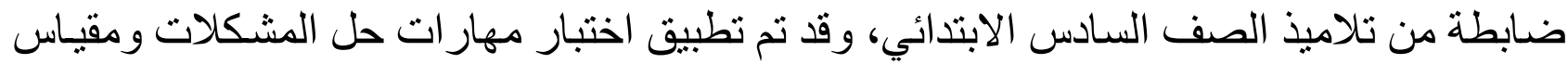

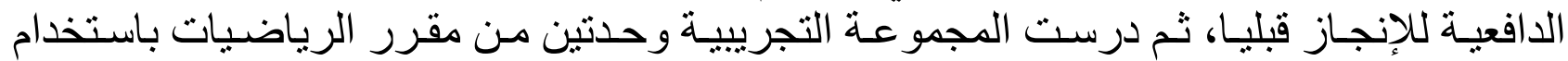

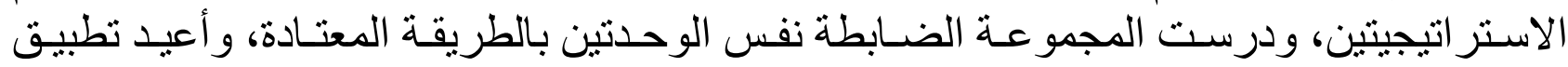

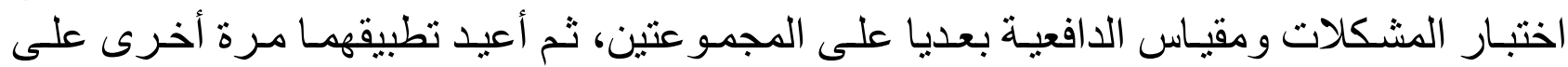

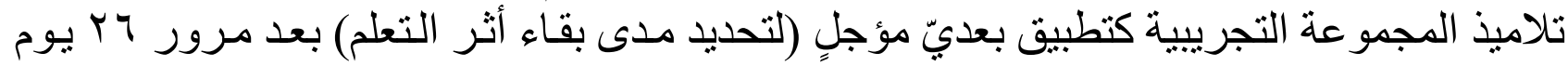

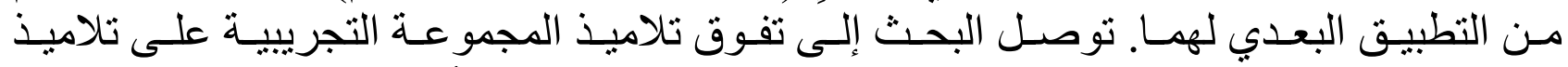

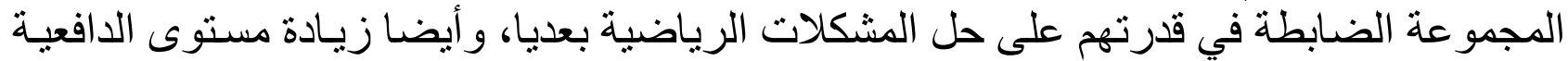

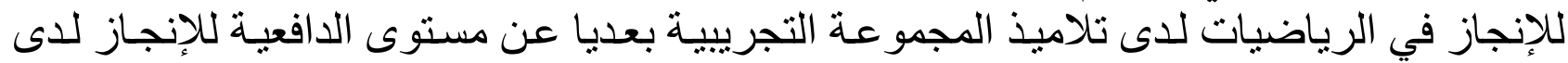

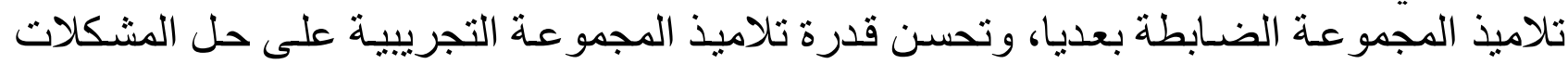

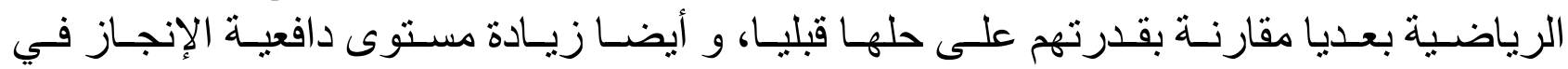
الرياضيات لدى تلامبذ المجمو عة التجريبيـة بعديا مقارنـة بمستوى دافعيتهم للإنجاز قبليـا، إضـافة فئة 
إلى بقاء أثزر التعلم بالنسبة للقدرة على حل المشكلات الرياضية لدى تلاميذ المجمو التحة التجريبية،

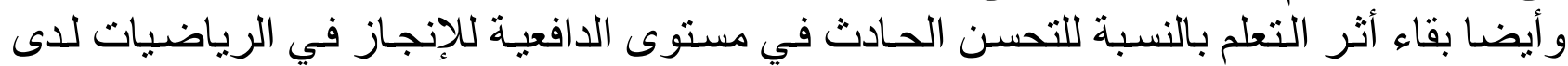
تلاميذ المجمو عة التجريبية.

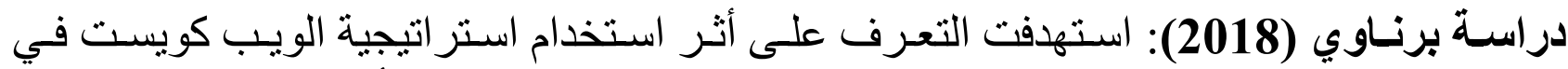

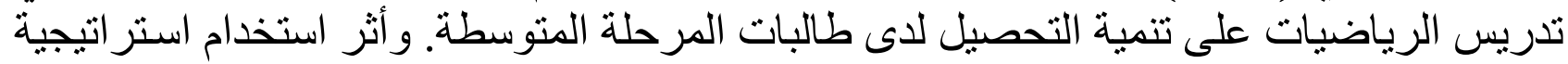

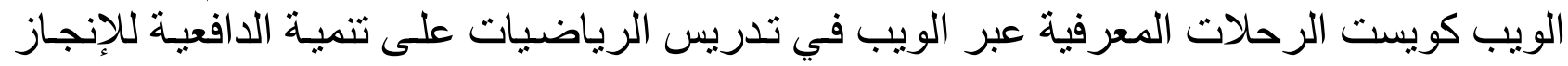

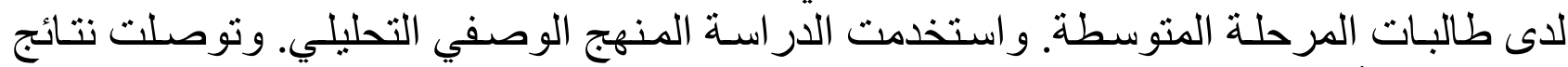

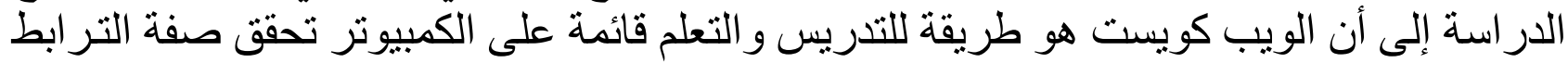

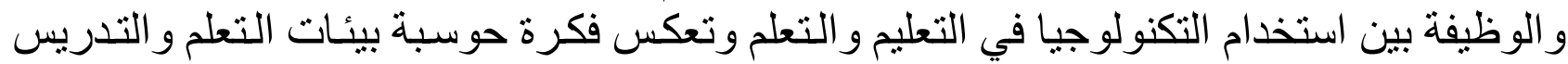

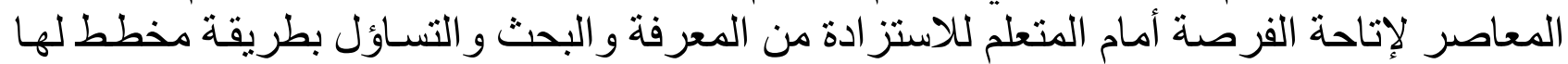

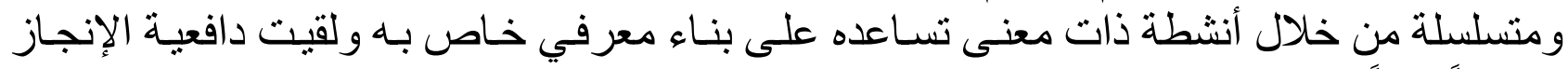

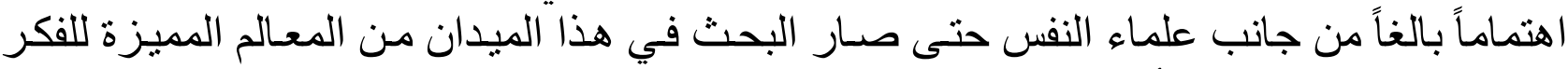

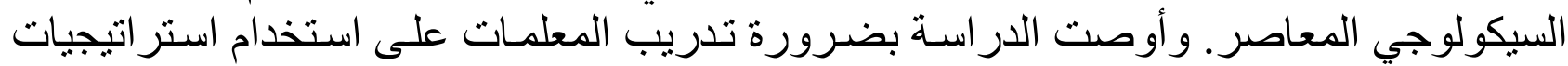

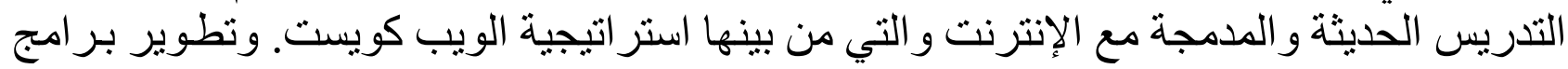

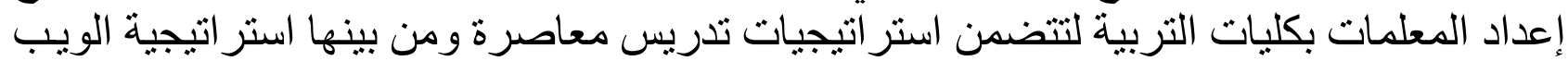
كويست

و أجرى عبدربـه (2017) در اسـة استتهدفت قياس الفاعلية النسبية لقبعـات التفكير الست و التعلم

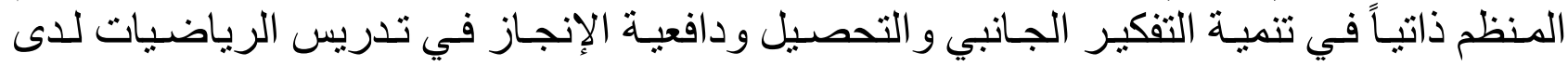

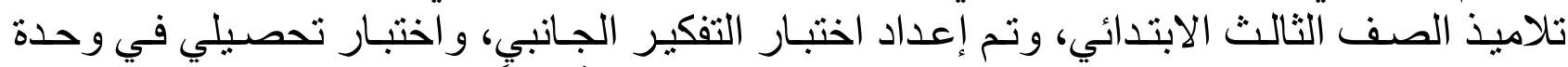

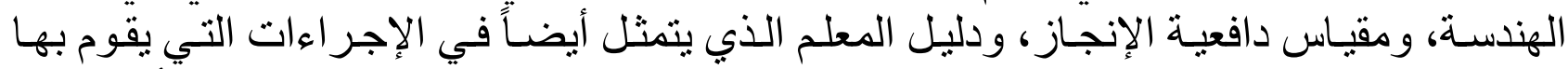

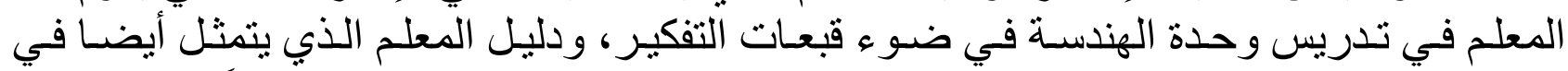

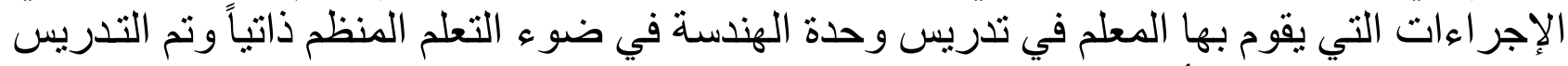

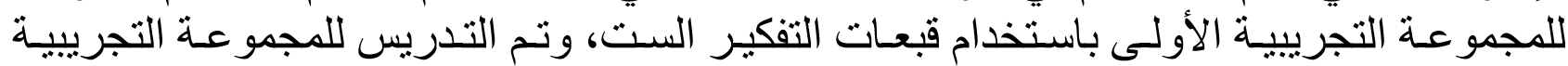

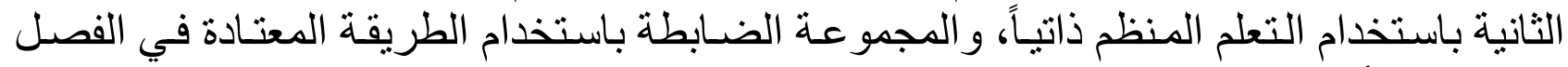

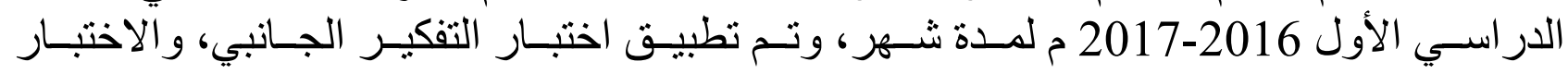

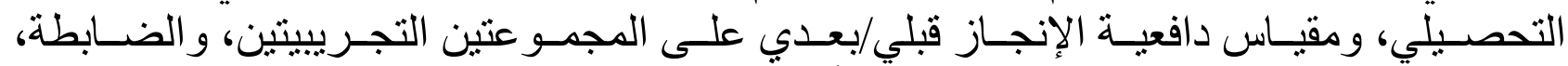

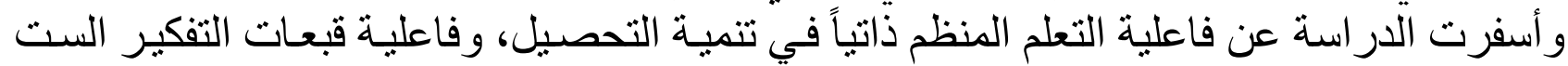

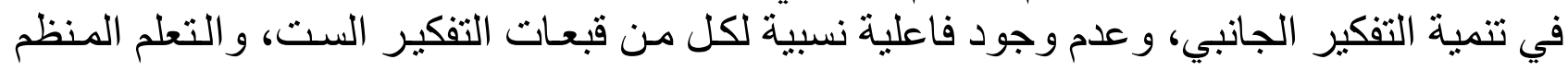
ذاتبا في تنمية دافعية الإنجاز

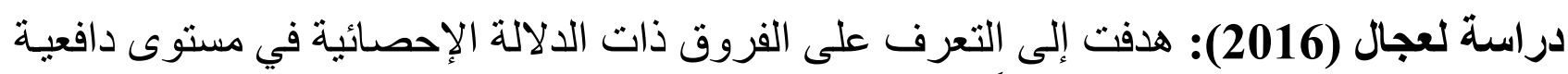

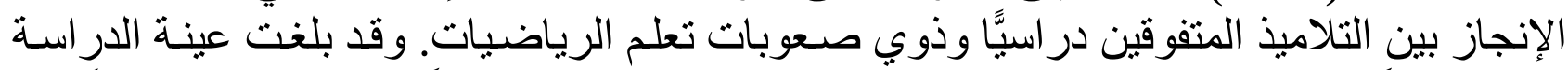

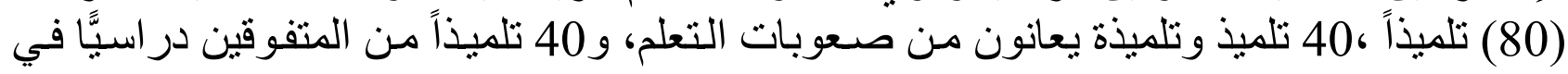

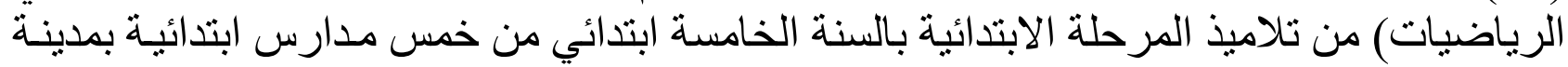

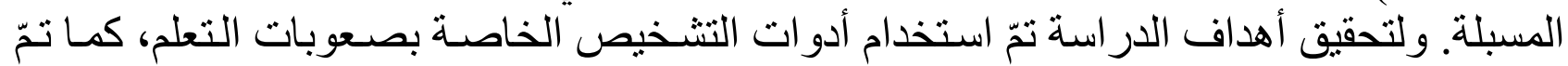

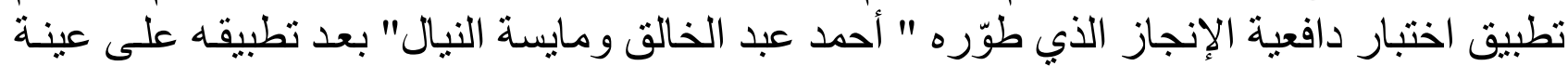
استطلاعية في البيئة المحلية وحصوله لإنه على دلالات صدق وثنبات عالية، ومن خلال تطبيق المنهج 


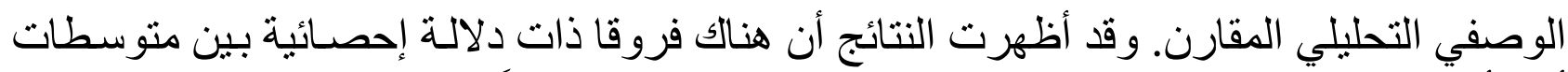

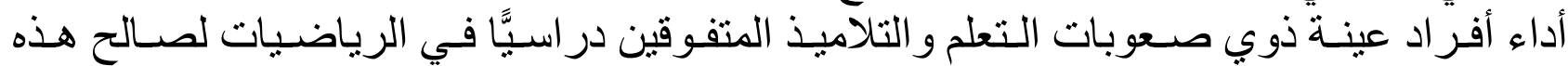

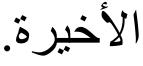

\section{منهج الدراسة:}

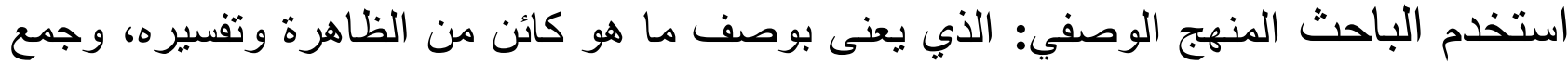

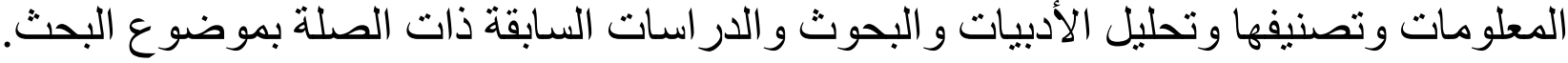

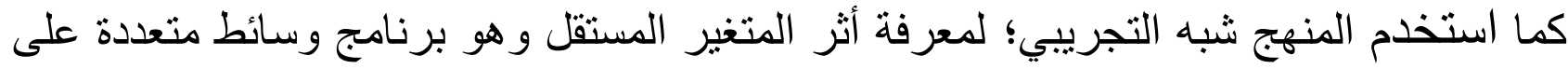

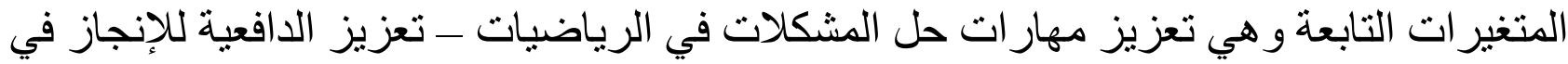
الرياضيات لدى طلاب الصف النئ السابع بمقاطعة شمال الثرقية.

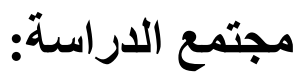

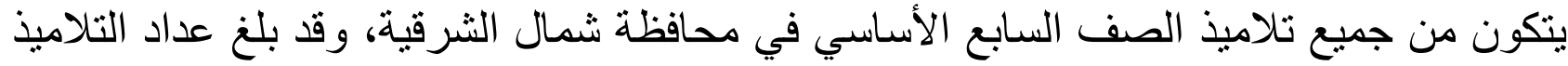
(2024) تلميذا، حسب بيانات قسم الإحصاء بالمديرية العامة للتربية و التعليم بشمال الثرقية (2019)، موز عين في مدن المحافظة. عينة الار اسة:

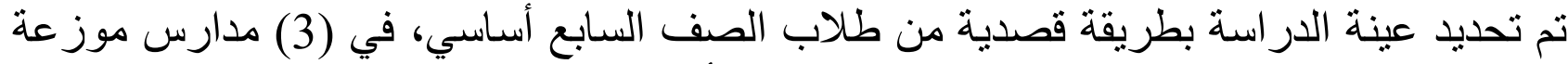

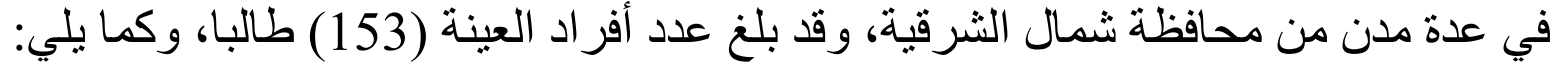

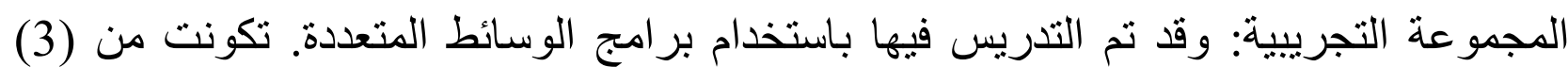

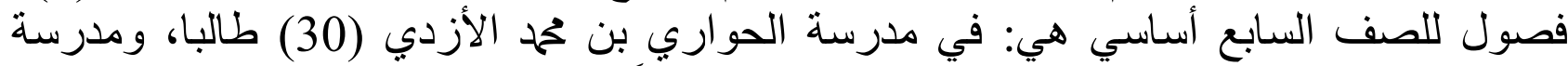
شبيب بن عطية (18) طالبا، ومدرسة الخير الخيرات (28) طالباً، المجموعة الضابطة: هي المجموعة التي لم تتعرض للمتغير التجريبي، حيث تم التدريس فيه

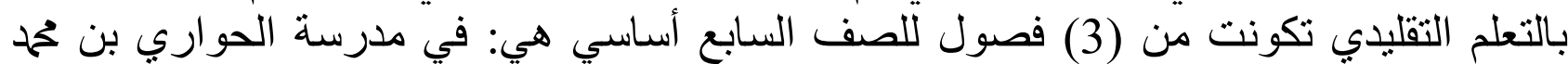

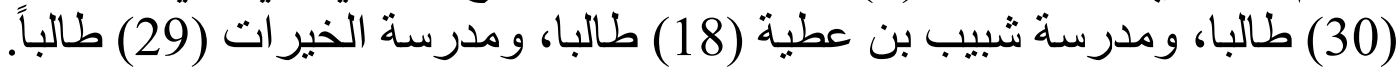

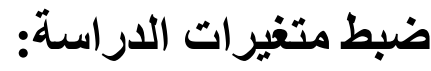

للتأكد من تكافؤ المجموعتين (التجريبية والضابطة)؛ قام الباحث بضبط عدد من المتغيرات

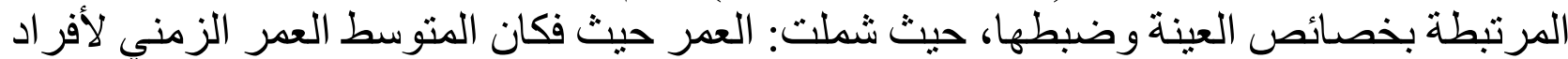

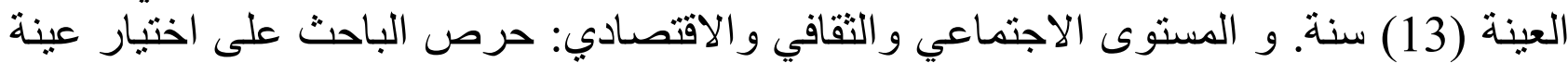

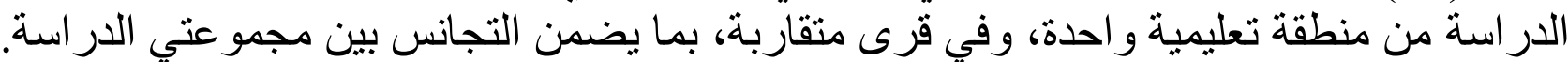

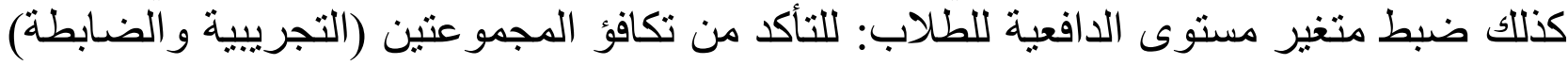

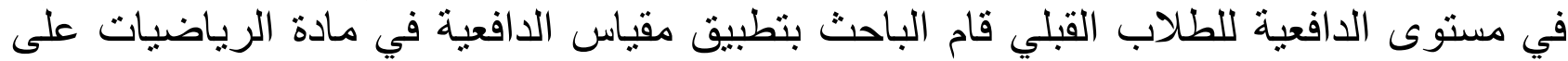

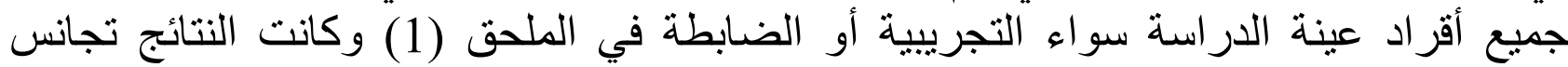
المجمو عتين في مستوى الدافعية بعد إجر اء اله عدة مقاييس.

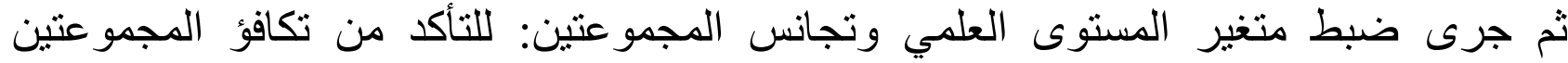
(التجريبية والضابطة) في المستوى التحصيلي و العلمي القبلي قام الباحث بمر اجعة نتائج الطلاب 
في مادة الرياضات لمدة عام كامل عن طريق المديرية العامة للتربية و التعليم بشمال الثرقية. إعداد وبناء الوحدة المحوسبة المقترحة:

جرى بناء الوحدة المحوسبة المقترحة (وحدة المساحة و المحيط) للصف السابع، لمعرفة فاعلية در اسة هذه الوحدة على أفر اد العينة في تتمية تحصيلهم في حل مشكلات واتجاة اتجاهاتهم نحو التعليم الاستخدام الوسائط متعددة ومقارنة ذلك مع الطلاب الذين يدرسون الوحدة ذاتها بالطريقة التقليدية. تم تطبيق الدرس وفق نموذج حمح خميس (2007): الذي يعد من النماذج الثـاملة لعمليات التصميم

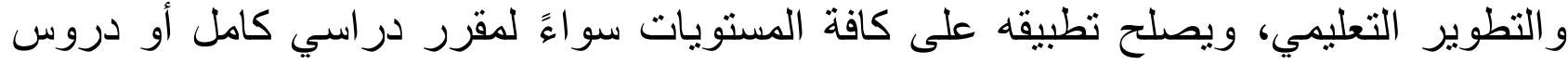
فردية. ويتناسب هذا النموذج مع البرنامج المستخدم في الدراسة من خلال خطواته ومراحله

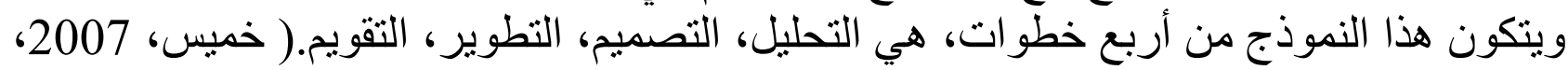

من أجل تحقيق أهداف الدراسة في الكثف عن أثر الوسائط المتعددة في تعزيز دافعية الإنجاز في الرياضيات بين طلاب الصف السـابع، والكثف عن اتجاهاتهم نحو الرياضيات، وذللك من خلالكل الوحدة السابعة للفصل الدر اسي الأول (المساحة و المحيط)؛ استخدم الباحث مقياس الدافعية للإنجاز في الرياضبات.

صدق الاختبار التحصيلي: للتحقق من صدق المحتوى قام الباحث بمر اجعة التوازن بين ما تشمله

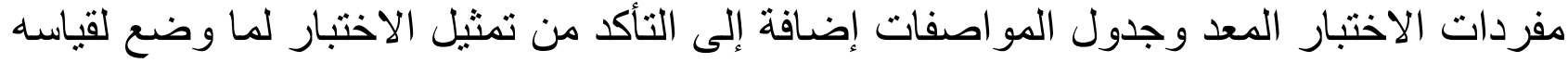
وسلامة التركيب اللغوي لمفرداته بحيث تعطي الدلالات المطلوبة. ثم قام الباحث بحساب معامل التمبيز لكل سؤال في الاختبار التحصيلي بهدف معرفة قدرة كيث سؤال في الاختبار التحصيلي على التمييز بين المجمو عتين العليا و الدنيا. حيث أثنار ملحم، (2005) أنه لكي يُعد السؤال مقبو لَّاً يجب أن يزيد معامل التميز عن (20\%) أما إذا أقل من ذلك فيجب التب تعديله.

\section{الاختبار التحصيلي في صورته النهائية:}

تكون الاختبار التحصيلي بصورته النهائية من (16) سؤ الاً، حيث بعطى لكل سؤ ال درجه درجتين

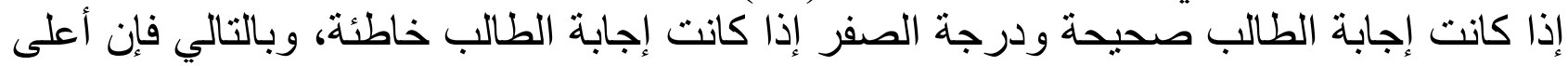
درجة يحصل علبها الطالب على الاختبار ككل هي (32) درجة و أقل درجة هي صفر. مقياس الدافعية للإنجاز في الرياضيات:

وضع الباحث مقياساً للتعرف على دافعية الإنجاز في الرياضيات لاى طلاب الصف السابع

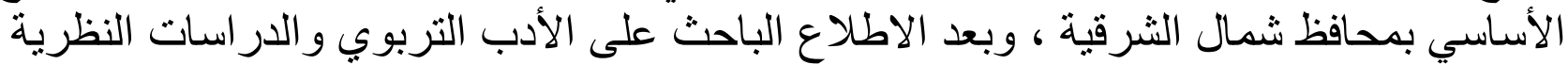

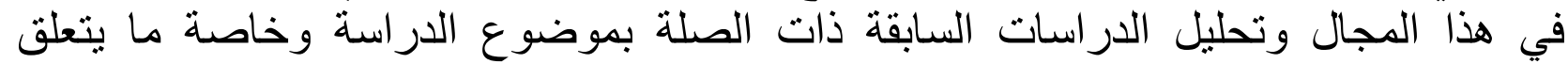
بالاتجاهات نحو الإنجاز في الرياضيات قام الباحث من باقتباس مقياس الدافعية في مادة Adnan Menderes University Aydin, الرياضبيات لدكتور التركي (2015) من جامعة Turkey يتكون المقياس من (33) فقرة متنوعة وبأربع خيار ات للإجابة (موافق بثدة موافق، معارض، معارض بشدة). وتم حساب صدق وثبات هذا المقياس على ضو هء الإجر اءات السابقة. وللتحقق من من من 
الخصائص السيكومثرية للمقياس المستخدم قام الباحث بحساب فاعلية فقرات المقياس (الاتساق الداخلي)، وذلك من خلال درجة الارتباط بين الفقرات و الدرجة الكلية لها. وقد اتضح أن جميع فقرات المقياس تتصف بمعامل ارتباط مرتفع ودال إحصائيا، مما يدلّ على صلاحية تطبيق ولئ المقباس.

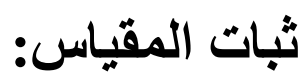

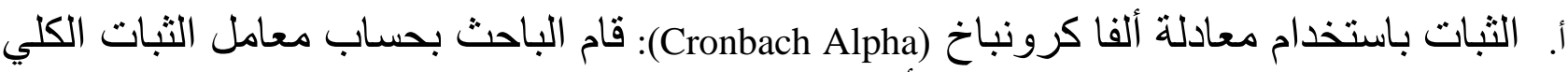
لمقياس الدافعية، حيث بلغ معدل معامل ألفا (0.937)، وهي قيمة مرتفعة مما بدل على صلاحية المقباس للتطبيق.

ب. الثبات بالتجزئة النصفية: تم التحقق من ثبات مقياس الدر اسة باستخدام طريقة التجزئة النصفية،

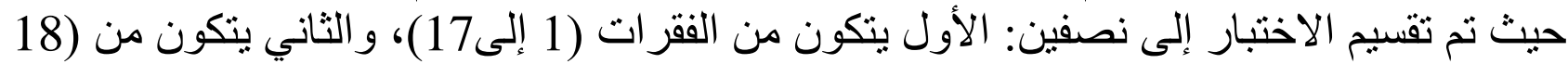

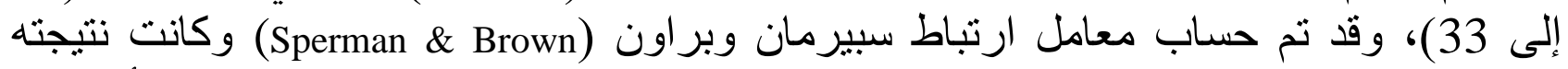

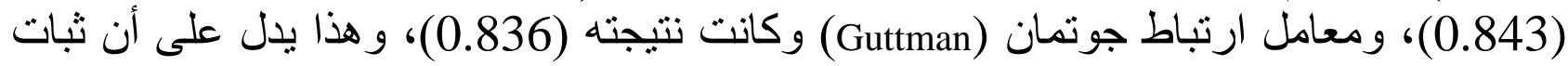

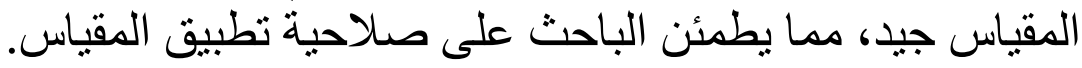

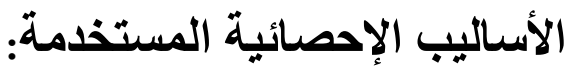

لحساب وجود فرق دال إحصائًا عند مستوي دلالة (0.05) بين متوسطي درجات القباسين القبلي

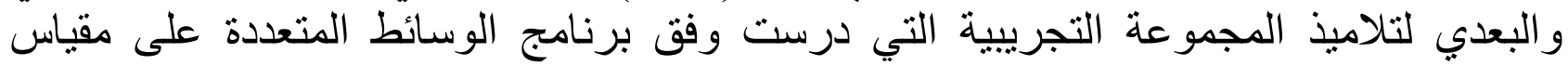
الدافعية للإنجاز في الرياضيات:

_المتوسطات الحسابية.Arithmetic Averages

ـالانحر اف المعياري Standard Deviation. ـمربع إيتا (2') لمعرفة حجم التأثير لبرنامج الوسائط المتعددة على المتغيرات التابعة. تثائج الدراسة: عرض التتائج المتعلقة بالسؤال الأول وتفسيرها: نص هذا السؤال على الاتي: ما مدى تأثثر الوسائط المتعددة على تحسين الدافعية للإنجاز في الرياضيات لدى طلاب الصف السابع في مقاطعة شمال الثرقية بسلطنة عُمان؟ وللإجابة عن هذا السؤ ال، تم استخر اج المتوسطات الحسابية والانحر اف المعياري وقيمة (ت)

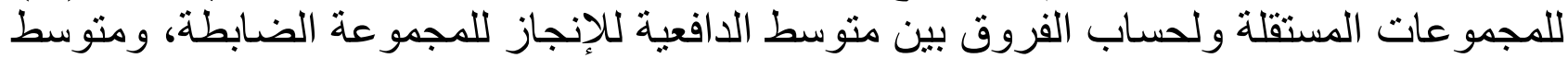
الدافعية للإنجاز للمجموعة التجريبية باستخدام الوسائط المتعددة في مادة الرياضيات، و الجدول الآتي بوضح ذلك.

جدول (1) المتوسطات الحسابية والانحر اف المعياري وقيمة (ت) لدرجات متوسط الدافعية

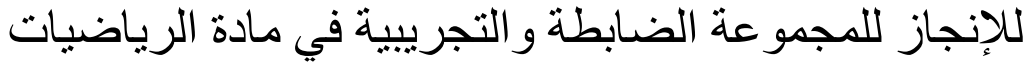

\begin{tabular}{|c|c|c|c|c|c|c|}
\hline مستوى الدلالة & قيمة ت & درجات الحرية & لانحرافي & المتوسطات الحسابية & العدد (ن) & المجموعة \\
\hline
\end{tabular}




\begin{tabular}{|c|c|c|c|c|c|c|}
\hline \multirow{2}{*}{0.00} & \multirow{2}{*}{-4.757} & \multirow{2}{*}{150} & 0.420 & 3.22 & 77 & الضـابطة \\
\hline & & & 0.321 & 3.51 & 75 & التجريبية \\
\hline
\end{tabular}

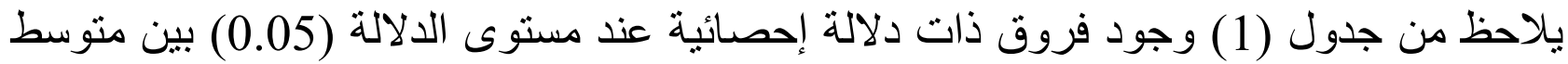

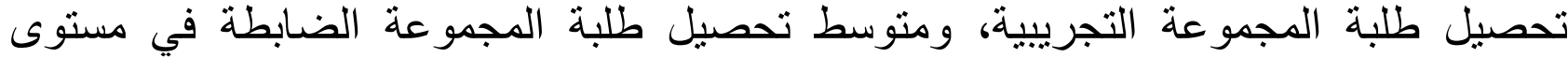
الدافعية للإنجاز في مادة الرياضيات، وجاءت الفرونة الفروق لصالح عينة طلبة المجموعة التجريبية،

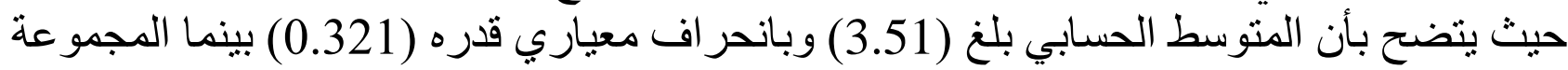

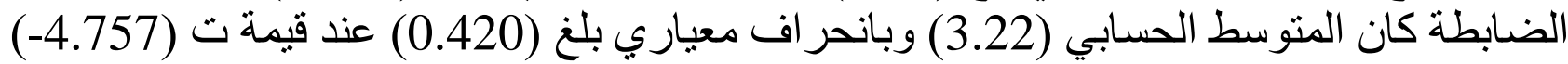
عند مستوى دلالة (0.00).

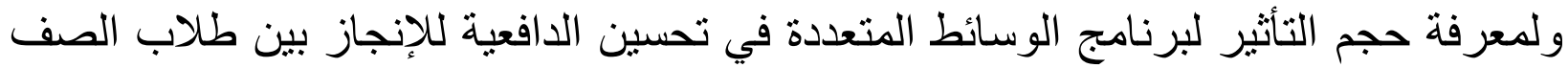

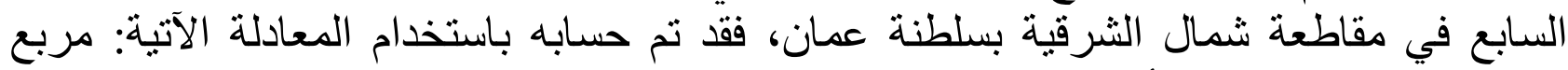

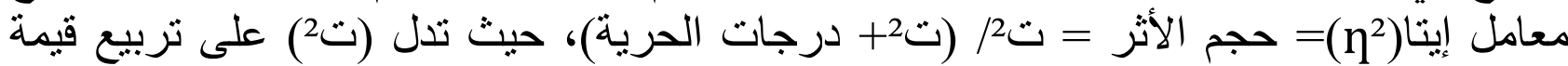
"ت"، كما يتحدد حجم الأثر على الأنر النحو الآتي:

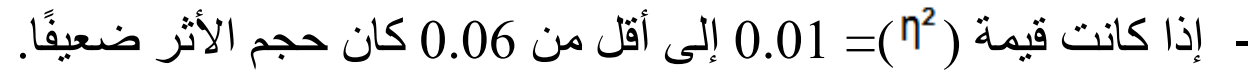

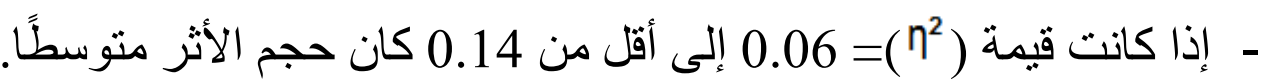
- إذا كانت قيمة ( يوضح الجدول الآتي نتائج حساب حجم الأثر: جدول (2) قيمة (n2) ومقدار حجم أثر برنامج الوسائط المتعددة في تحسين دافعية الإنجاز في

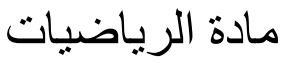

\begin{tabular}{|c|c|c|c|c|c|}
\hline مقدار حجم & قيمة (n) & درجات & قيمة "ت" & التابغير & المستقلير \\
\hline متوسط & 0.131 & 150 & -4.757 & الإنجاز & الوسائط \\
\hline
\end{tabular}

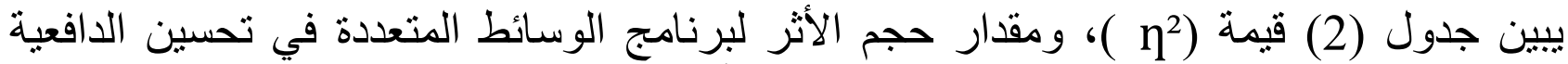

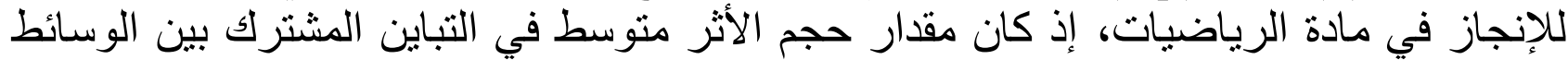

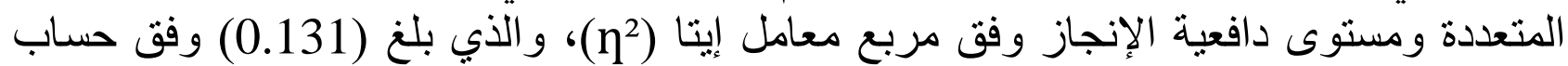
مربع معامل إيتا(n) الآتية:

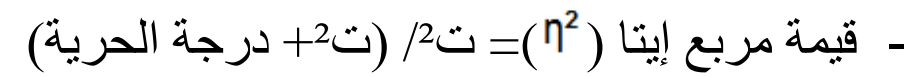
- قيمة مربع إينا (150+ (-4.757) - $0.131=\left(\eta^{2}\right)$ 
حيث يلاحظ أن قيمة مربع معامل إيتا (n²) جاءت بين (0.06) و(0.14) وهي متوسطة التأثير،

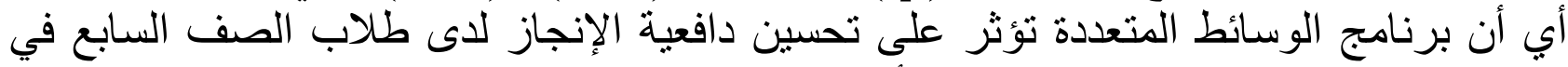

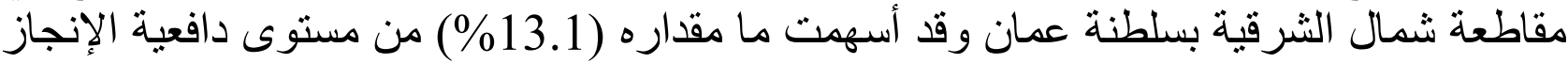

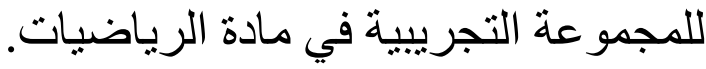

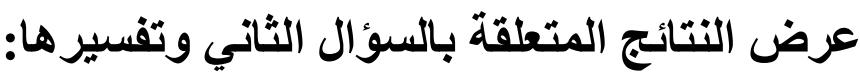

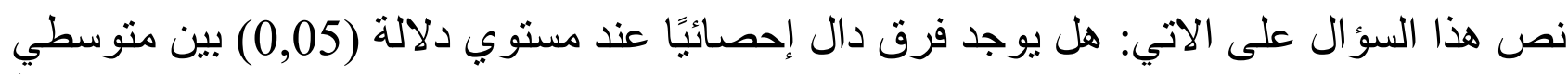

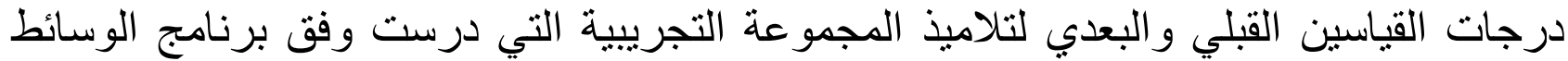

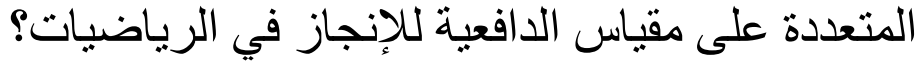

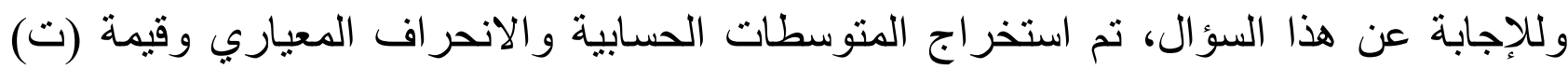

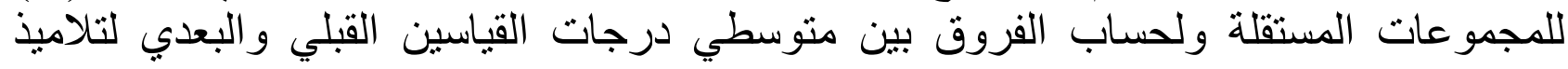

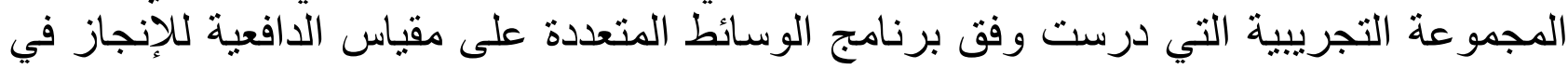
الرياضيات، وجدول الاتي يوضح ذلتك

جدول (3) المتوسطات الحسابية و الانحر اف المعياري وقيمة (ت) بين متوسطي درجات القياسين

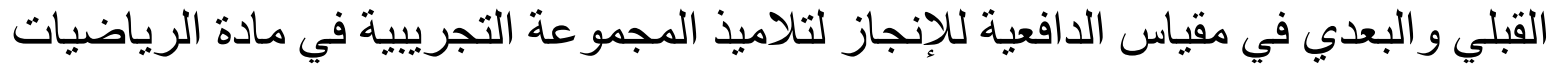

\begin{tabular}{|c|c|c|c|c|c|c|}
\hline مستوى الدلالة & قيمة ت & الحرية & الالحياري & المتوسطات الحسابية & العدد (ن) & المجمو عة \\
\hline \multirow{2}{*}{0.00} & \multirow{2}{*}{-12.750} & \multirow{2}{*}{168} & 0.394 & 2.81 & 78 & القبلية \\
\hline & & & 0.316 & 3.52 & 76 & البعدية \\
\hline
\end{tabular}

يلاحظ من جدول (3) وجود فروق ذات دلالة إحصائية عند مستوى الدالة (0.05) بين متوسطي

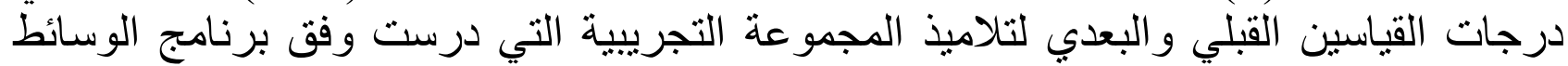

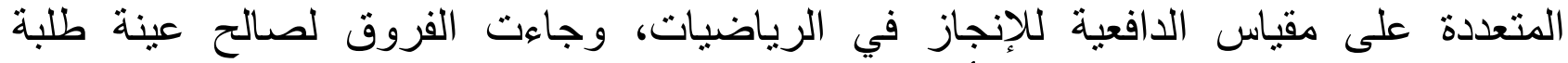

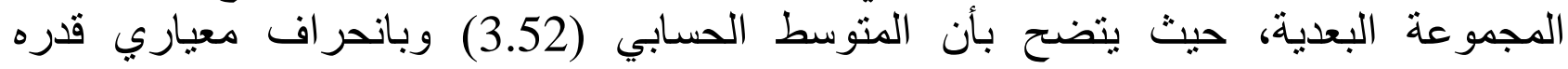

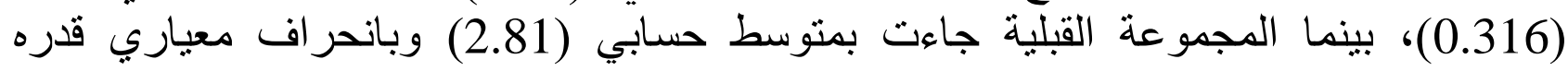
(0.394) عند قيمة ت (12.750) (12.316) ومستوى الدلالة (0.00).

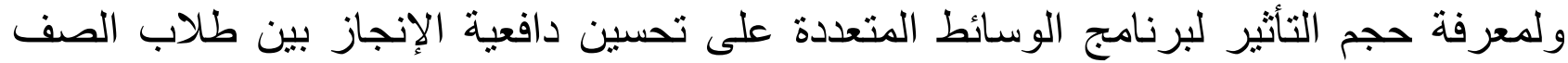

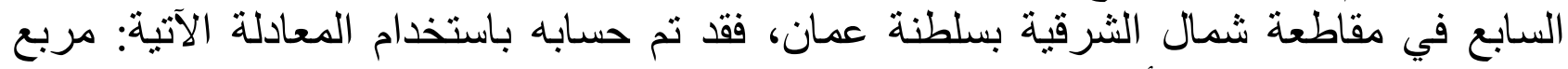

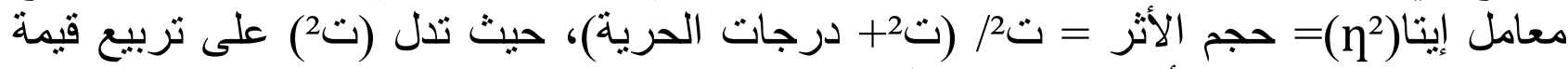

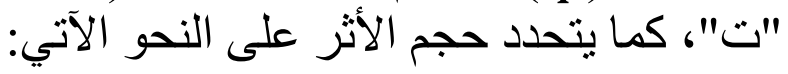
-

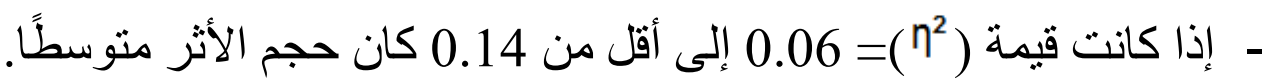
- إذا كانت قيمة ( 
يوضح الجدول الآتي نتائج حساب حجم الأثر: جدول (4) قيمة (12) ومقدار حجم أثر برنامج الوسائط المتعددة على تحسين دافعية الإنجاز في الري

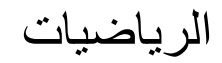

\begin{tabular}{|c|c|c|c|c|c|}
\hline حجم الأثر & قيمة (n) & درجات الحرية & "قيمة" & المتغير التابع & المتغير المستقل \\
\hline كبير & 0.492 & 168 & -12.750 & دافعية الإنجاز & الوسائط المتعددة \\
\hline
\end{tabular}

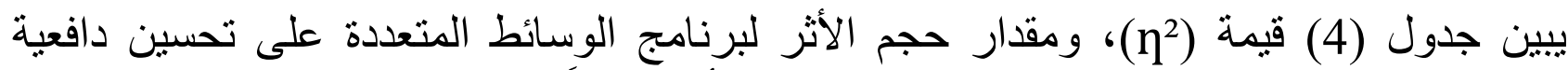

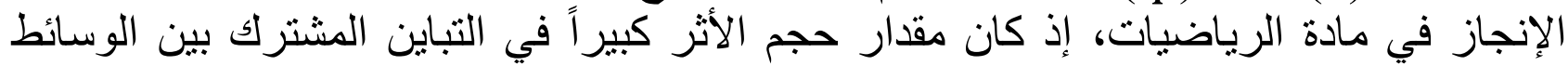

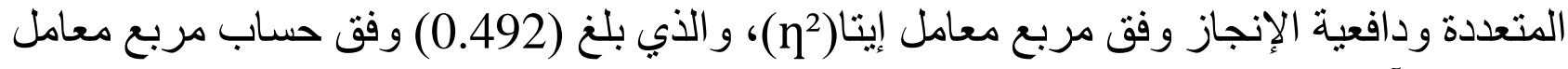
إينا) الآنآنية:

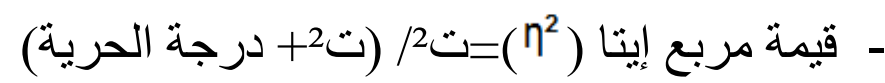

$$
\begin{aligned}
& \text { - قيمة مربع إيتا (168 } \\
& \text { - } 0.492=\left(\eta^{2}\right)
\end{aligned}
$$

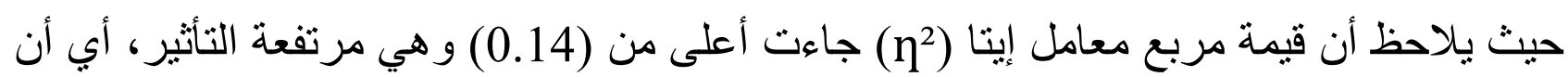

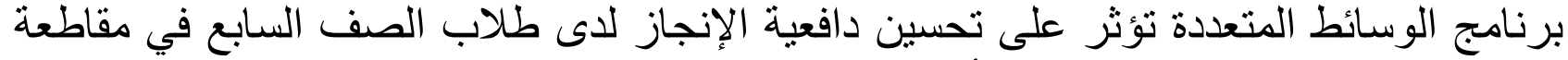

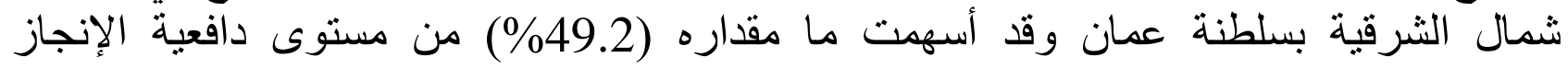

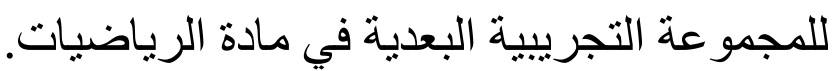

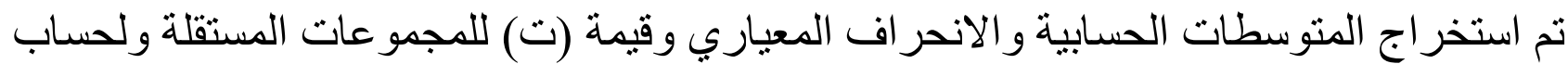

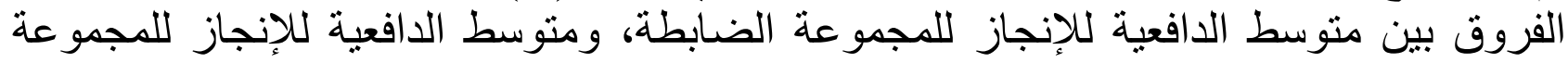

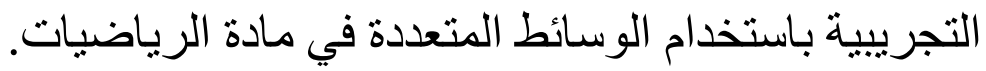

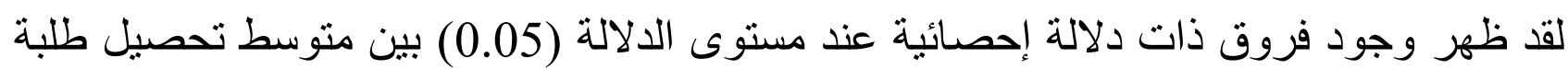

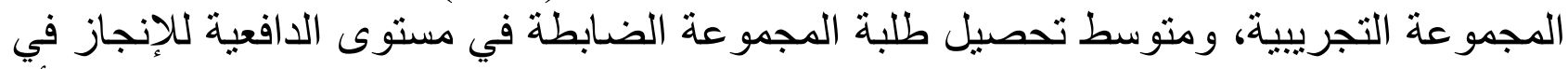

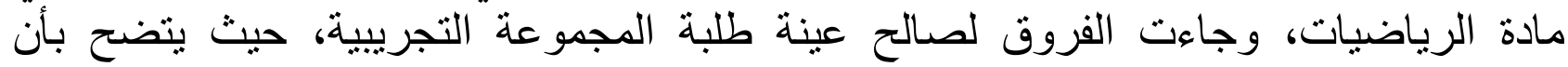

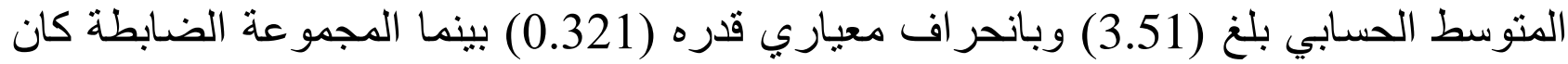
المنوسط الحسابي) 3.22) وبانحر اف معياري بلغ (0.00) (0.420) عند قيمة ت (0.321) (4.757-) عند مستوى دلالة (0.00).

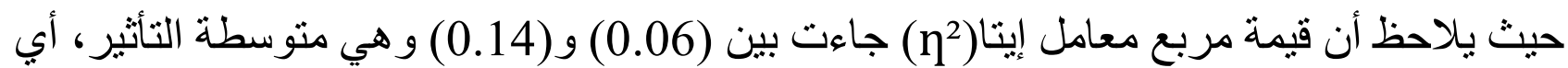

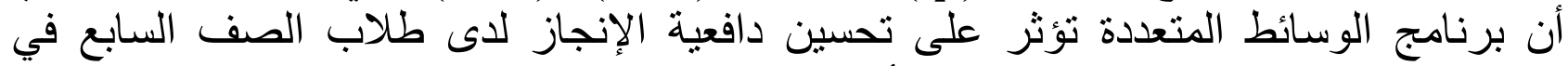

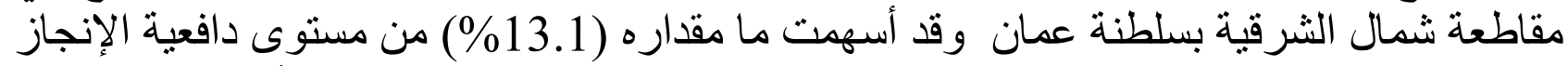

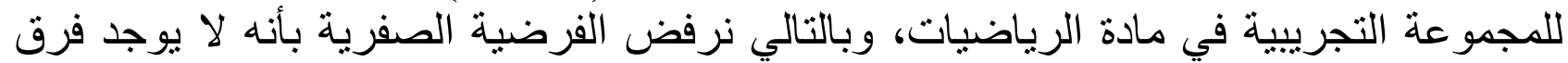

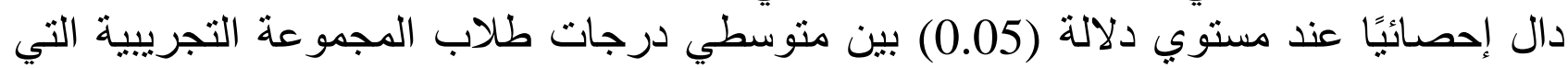

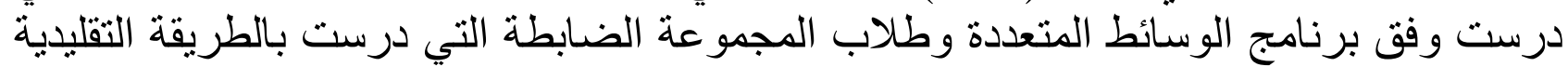

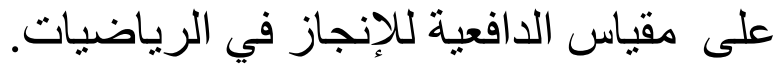

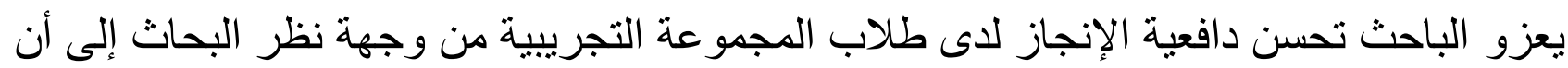


البرنامج راعى الفروق الفردية وتوجهات الطلاب نحو عالم التقنية والاتصالات وكذللك أزال

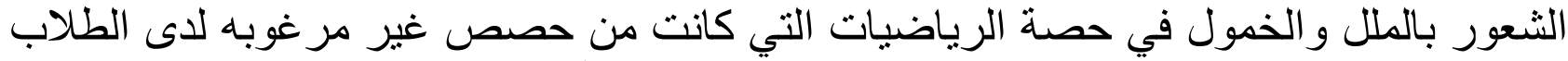

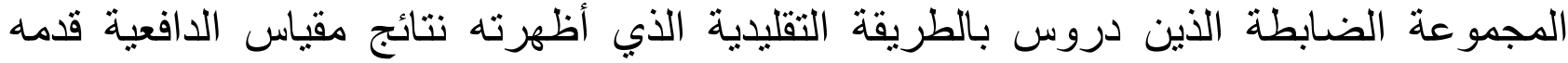

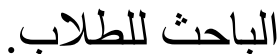

ومن الأشياء التي أدت إلى رفع دافعية الإنجاز لإى طلاب هو حب الطلاب استخدام الأجهزة الإلكترونية في الحصة والمشاركة في حل التمارين وان استخدام الوسائط المتعددة بأنثكالها

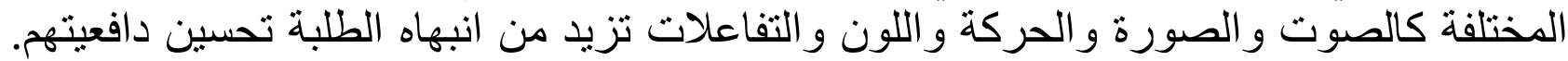

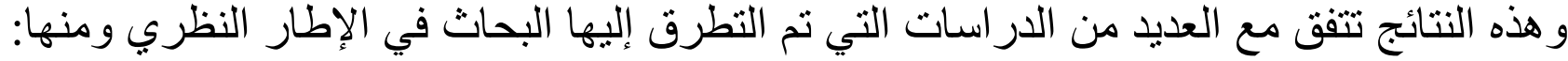

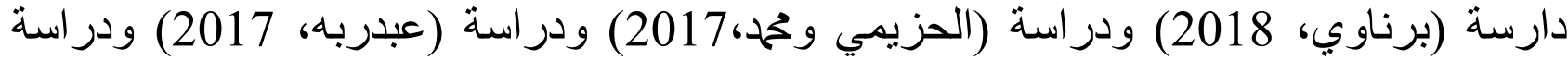

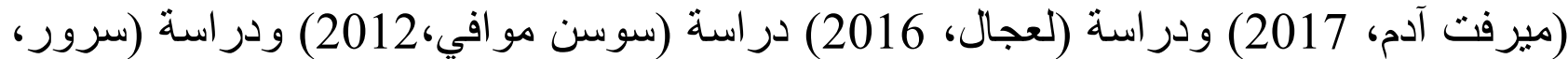
2009)، و غير ها من الدر اسات التي أكدت جميعها على أثر البرمجيات التئ التعلمية في تحسن دافعية

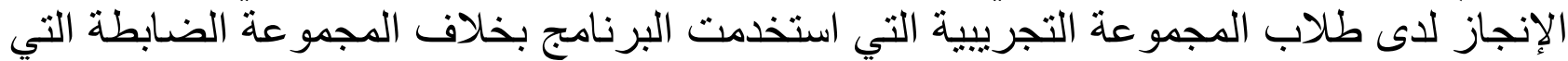
استخدمت الطريقة التقليدية. ويمكن تفسير هذه النتيجة:

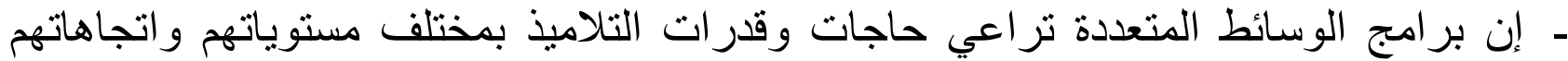

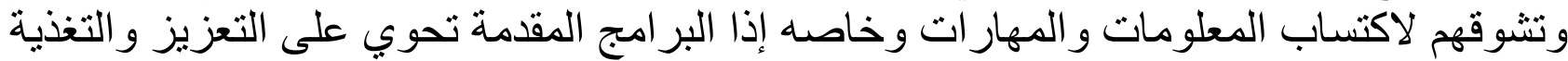

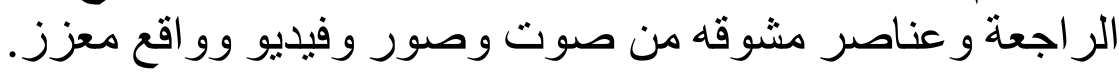

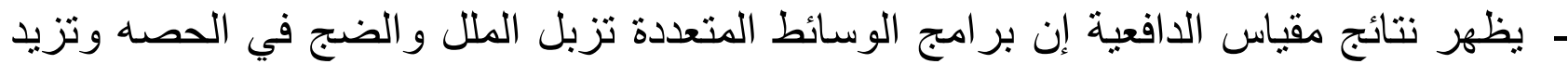
الرغبة في المشاركة بالأنشطة في حصة الرغة الرياض براضيات.

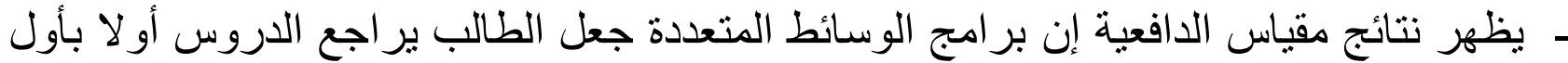

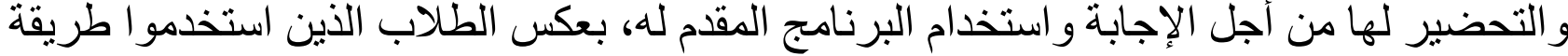
التدريس التقليدية.

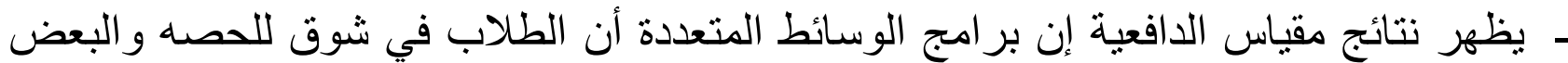

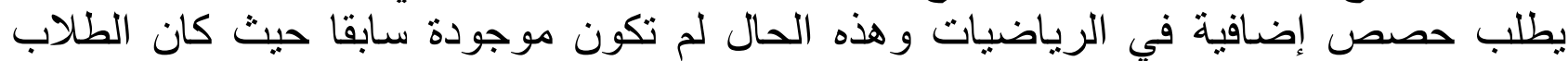
ينفرون من حصص الرياضيات.

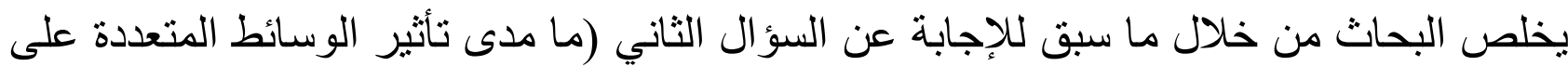

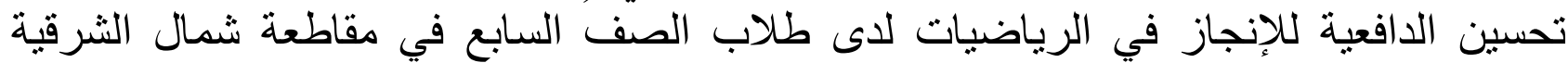

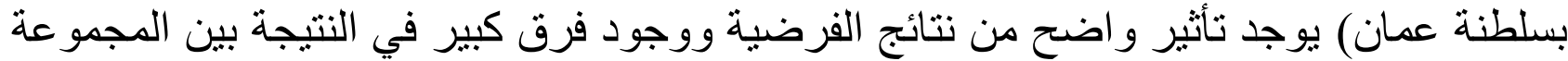
التجريبية والضابطة لمصلحة التجرييية التي درست باستية باتخدام الوسائط المتعددة.

\section{عرض النتائج المتعلقة بالسؤال الثالث وتفسير ها:}

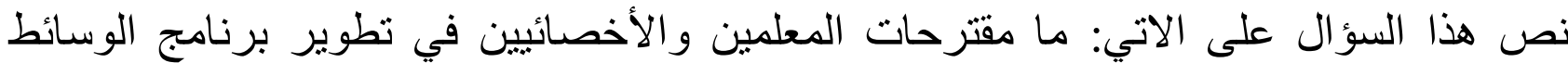

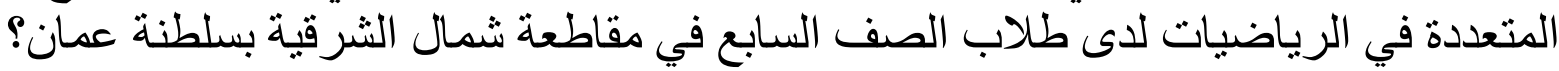

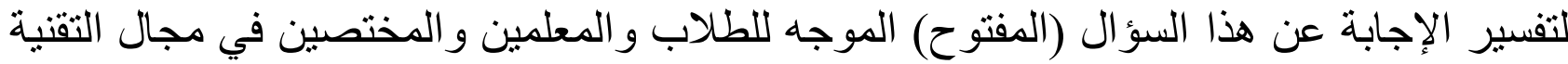

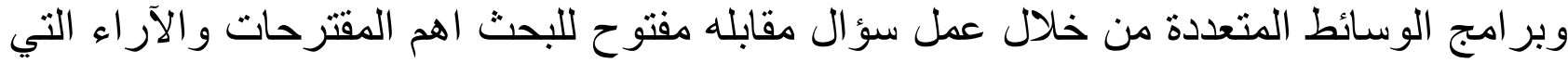


تهدف إلى تطوير بر امج الوسائط المتعددة في مختلف أنو اعها في مادة الرياضيات.

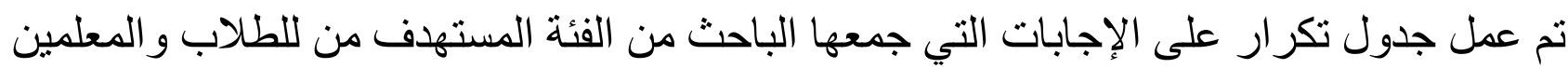

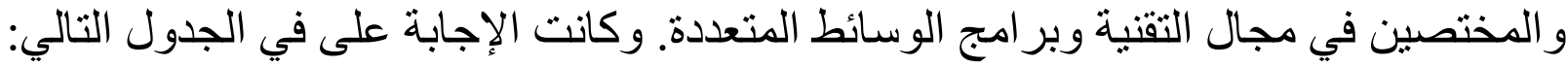

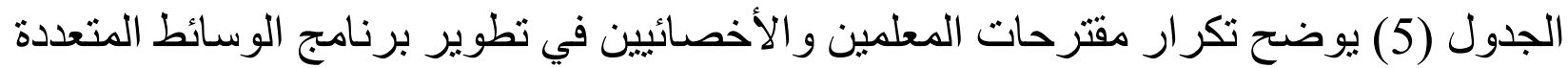

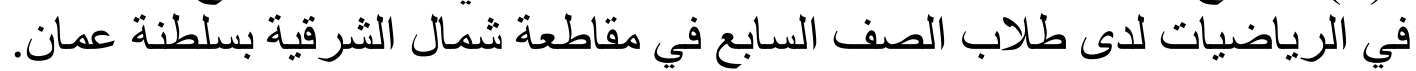

\begin{tabular}{|c|c|c|}
\hline ت تكرار & المقترحات & b \\
\hline 5 & إنشاء تطبيقات تفاعلية تخدم مادة الرياضيات & 1 \\
\hline 3 & دروس مباشرة (أون لاين) & 2 \\
\hline 7 & توفير أدوات وأجهزه في كل قاعه & 3 \\
\hline 4 & تعميم هذه التجربة في الددارس (تبني وزارة التربية الفكرة) & 4 \\
\hline 5 & توفير شبكات إنترنت في كل قاعه تدريسية & 5 \\
\hline 3 & عمل إلعاب تعليمية في الرياضيات & 6 \\
\hline 3 & التنويع في بر امج التدريس لتحميس الطلاب على فهم الدرس & 7 \\
\hline 2 & في الرياضيات مشاغل وورش في كيفية استخدام برنامج الوسائط المتعددة & 8 \\
\hline 1 & إعداد دروس الكرتونية مساعده لتدريس الرياضيات & 9 \\
\hline 1 & توفير مختبر خاص لمادة الرياضيات مثل باقي مو اد العلوم & 10 \\
\hline
\end{tabular}

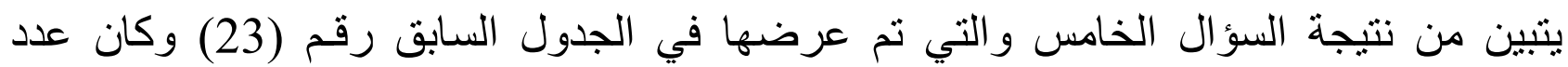

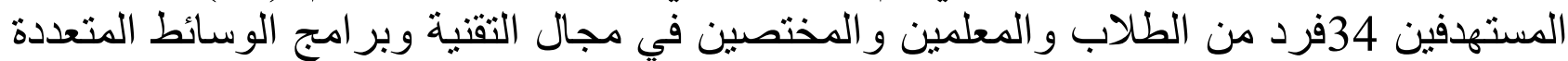

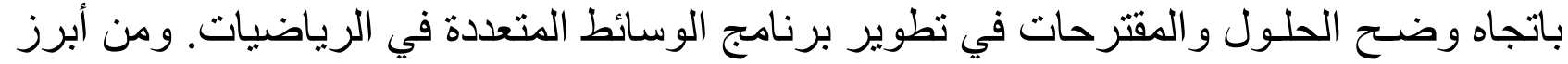

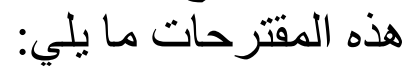
أ. إنشاء تطبيقات تفاعلية تخدم مادة الرياضيات

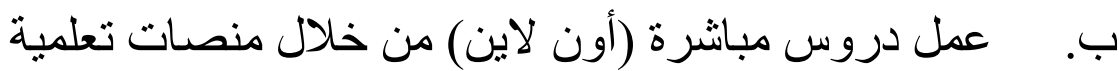

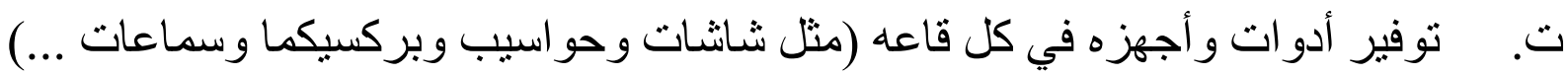
ث. ت تعميم هذه التجربة في المدارس (تبني وزارة التربية الفكرة) ج.نوفير شبكات إنترنت في كل قاعه تدريسية نستتتج من استجابات التي تم تجميعها من هذا السؤال: أن هنالك رضى كني كبير في الأوساط التعلئيمية

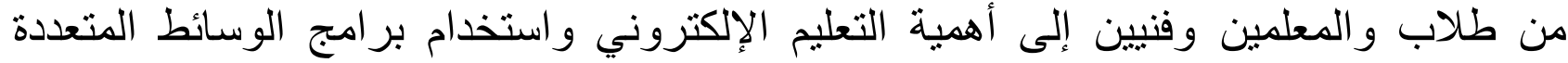


وتطبيقات في الهواتف الذكية التي تجعل التعليم أفضل وأسهل ويراعي جميع المستويات

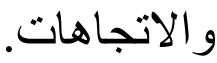

و هذه النتائج تتفق مع العديد من الدر اسات التي تم التطرق إليها البحاث في الإطار النظري ومنها:

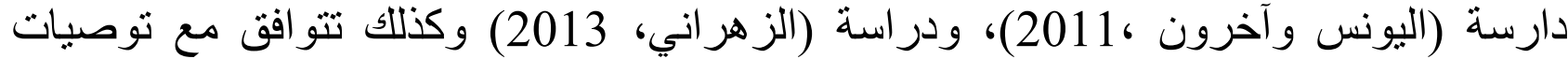

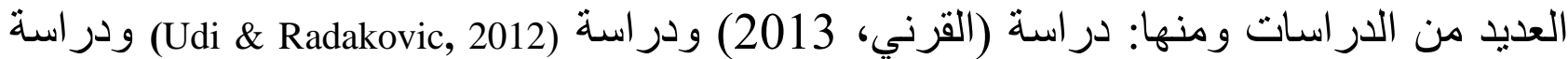

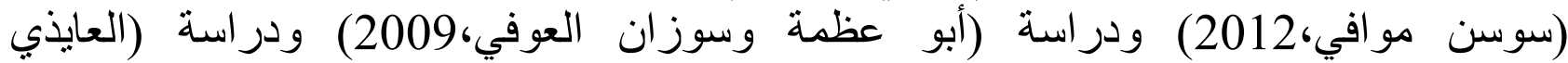
و الرياثي،2014) و غير ها من الدر اسات التي أكدت جميعها أو بعضها التهانه انه لا بد من تطوير التعليم

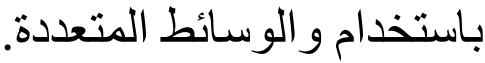

قائمة المراجع:

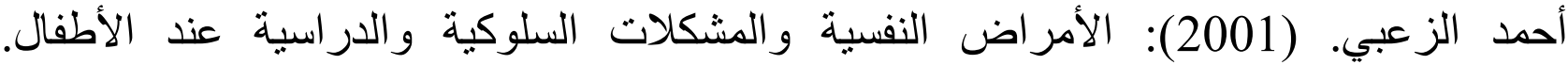
السعودية: دار زهر ان للنشر و التوزيع.

آدم، ميرفت محم كمال محمد (2014). "فعالية وحدة تدرييية في عادات العقل في تنمية التحصيل

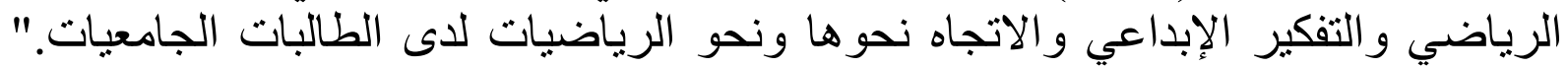

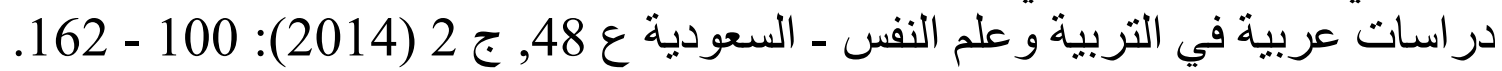
البركاتي، نيفين بنت حمزة شرف. (2014) "أثر استخدام برنامج تدريبي قائم على التدريس الفعال

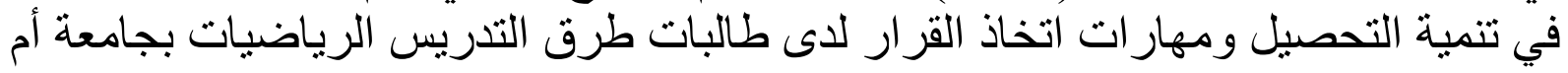

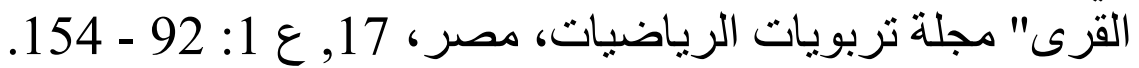

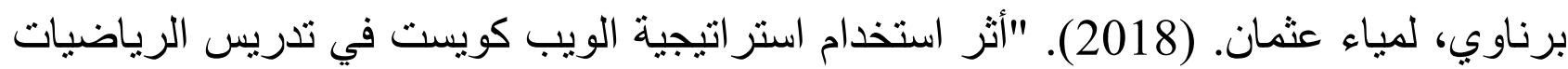

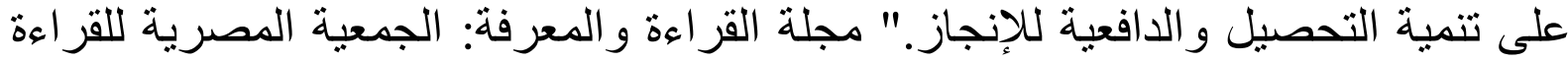

$$
\text { و المعرفة عالي تصنة 1989: } 229 \text { - } 263 .
$$

خميس، ححم عطية. (2007). الكمبيونر التعليمي وتكنولوجيا الوسائط المتعددة. القاهرة: مكتبة دار السحاب للنشر و التوزيع. (النمان.

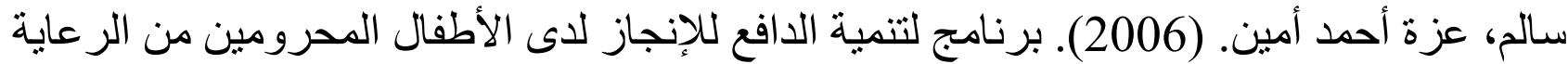
الو الدية، رسالة ماجستير غير منشورة، معهد الدر اسات و البحوث التربوية، جامعة القاهرة.

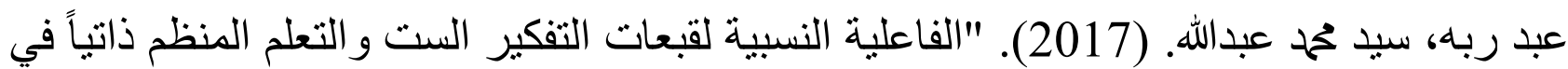

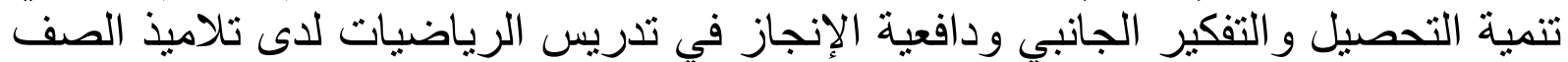
الثالث الابتدائي." مجلة تربويات الرياضيات: الجمعية المصرية لترية لتربويات الرياتيات لرياضيات

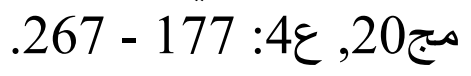

عسيرى، عبد الله على عبد الله آل عواض. (2016). "أثر تدريس الرياضيات باستخدام إستراتيجية الجدول الذاتي في تحصيل طلاب الصف الخامس الابتدائي بمدارس خميس

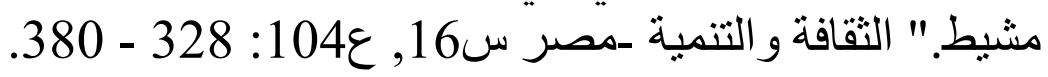
عياد، منى خالد محمود. (2008). أثر برنامج بالوسائط المتعددة في ضوء نظرية الذكاءات 
المتعددة على اكتساب المفاهيم التكنولوجية وبقاء أثر التعلم لدى طالبات الصف السابع بغزة،

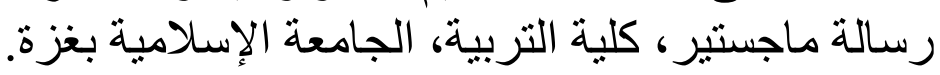

فتح الرحمن، عازة حسن، ومختار عثمان الصديق. (2010). "الإبداع في التدريس الجامعي باستخدام الوسائط المتعددة." المجلة العلمية ـ جامعة الزعيمة عيم الأزهري ـ السودان ع8: 46 ــ

لعجال، سعيدة. (2016). "دراسة مقارنة لدافعية الإنجاز بين التلاميذ المتفوقين دراسيا وذوي

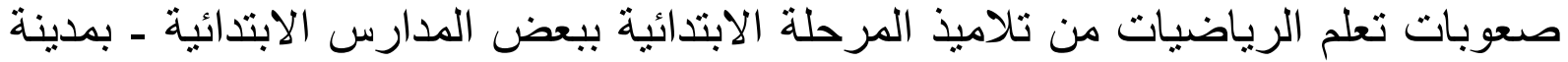

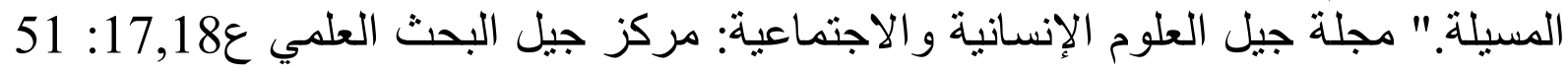
$.70-$ ملحم، سامي. (2005). القياس و التقويم في التربية و علم النفس، دار المسيرة، عمان، الأردن النجدي، أحمد عبد الرحمن. (2015) المنهج في عصر ما بعد الحداثة، ط3، دار الأقصى للطباع، القاهرة.

وزارة التربية و التعليم. (2018) التقرير الوطني للدراسة الدولية في الرياضبيات و العلوم (2015 .(TIMSS

\section{ARABIC REFERENCES IN ROMAN ALPHABET}

'Ahmad Alzaebi. (2001): Al'amrad Alnafsiat Walmushkilat Alsulukiat Waldirasiat Eind Al'atfal. Alsewdit: Dar Zahran Lilnashr Waltawzie.

Adam, Mirafat Muhamad Kamal Muhamad (2014). "Fealiat Wahdat Tadribiat fi Eadat Aleaql fi Tanmiat Altahsil Alriyadii Waltafkir Al'iibdaeii Walaitijah Nahwaha Wanahw Alriyadiaat Ladaa Altaalibat Aljamieiaat." Dirasat Earabiat fi Altarbiat Waealam Alnafs - Alsewdyt E 48, J 2 (2014): 100 - 162.

Alburkati, Nyfyn Bnt Hamzatan Bin Sharaf. (2014). "lathar Aistikhdam Barnamaj Tadribiin Qayim Ealaa Altadris Alfaeeal fi Tanmiat Altahsil Wamaharat Aitikhadh Alqarar Ladaa Talibat Turuq Altadris Alriyadiat Bijamieat 'Ama Alquraa." Majalat Tarbawiat Alriyadiat -Msr Maj 17, E 1: 92 - 154.

Barnawi, Limia' Eithman. (2018). "'Athur Aistikhdam 'listratijiat Alwayb Kawayst Fi Tadris Alriyadiaat Ealaa Tanmiat Altahsil Waldaafieiat Lil'iinjazi." Majalat Alqira'at Walmuearfata: Aljameiat Almisriat Lilqara'at Walmaerifat Ea198: 229 - 263.

Khamis, Muhamad Eatia. (2007). Alkimbiutir Altaelimiu Watiknulujia Alwasayit Almutaeadidata. Alqahrt: Maktabat Dar Alsahab Lilnashr Waltawzie.

Salim, Eizat 'Ahmad 'Amyn. (2006). Barnamaj Litanmiat Alddafie Lil'iinjaz Ladaa Al'atfal Almahrumin Min Alrieayat Alwaldiati, Risalat Majsatayr Ghyr Munshurat, Maehad Aldirasat Walbihwith Altarbawiati, Jamieat Alqahirat.

Eabd Rbh, Sayid Muhamad Ebdallh. (2017). "Alfaeiliat Alnisbiat Liqabaeat Altafkir Alst Waltaelim Almunazam Dhatyaan Fi Tanmiat Altahsil Waltafkir Aljanibii Wadafieiat Al'iinjaz Fi Tadris Alriyadiat Ladaa Talamidh Alsaf Alththalith Alaibtidayiy." Majalat Tarbawiat Alriyadiat: Aljameiat Almisriat Litarbuiat Alriyadiaat Mj20, E4: 177 - 267.

Easayraa, Eabd Allah Ealaa Eabd Allah Al Eawwad. (2016). "Athur Tadris Alriyadiaat Biastikhdam 'listratijiat Aljadwal Aldhdhatii fi Tahsil Tullab Alsafi Alkhamis Alaibtidayiyi Bimadaris Khamis Mashit." Althaqafat Waltanmiat -Msur Sa16, Ea104: 328 - 380.

Eiadi, Munaa Khalid Mahmud. (2008). 'Athar Barnamaj Bialwasayit Almutaeadidat Fi Daw' Nazariat Aldhikaa'at Almutaeadidat Ealaa Aiktisab Almafahim Altiknulujiat Wabiqa' 'Athar Altaelum Ladaa Talibat Alsafi Alssabie Bighizati, Risalat Majstir, Kuliyat Altarbiati, Aljamieat Al'iislamiat Bighazat.

Fath Alrhmn, Eazat Hsn, Wamukhtar Euthman Alsadiqi. (2010). "Al'iibdae Fi Altadris Aljamieii Biastikhdam Alwasayit Almutaeadidati." Almajalat Aleilmiat - Jamieat Alzaeim Al'azhari - Alsuwdan E8: 46 - 63. 
Leajal, Saeid. (2016). "Drast Mqarnt Lidafieiat Al'iinjaz Bayn Altalamidh Almutafawiqin Dirasiaan Wadhuii Sueubat Taelam Alriyadiat Min Talamidh Almarhalat Alaibtidayiyat Bibaed Almadaris Alaibtidayiyat Bimadinat Almsyl." Majalat Jil Aleulum Al'iinsaniat Walaijtimaeiat: Markaz Jil Albahth Aleilmii E17,18: $51-70$.

Malham, Sami. (2005). Alqias Waltaqwim Fi Altarbiat Waealam Alnafsi, Dar Almasirat, Eaman, Al'urdun.

Alnajdi, 'Ahmad Eabd Alrahmun. (2015) Almunahj Fi Easr Ma Baed Alhadathat, Ta3, Dar Al'aqsaa Liltibae, Alqahirat.

Wizarat Altarbiat Waltaelim. (2018) Altaqrir Alwataniu Lildirasat Alduwaliat Fi Alriyadiat Waleulum (2015 Timss). Saltanat Eimaana: Almudiriat Aleamat Litatwir Almunahij.

\section{REFERENCES}

Chung, I. (2004). A comparative assessment of constructivist and traditionalist approaches to establishing mathematical connections in learning multiplication education. Dissertation abstract International.

Thomas K.F. Chiu, Ida A.C. Mock (2017) Learner expertise and mathematics different order thinking skills in multimedia learning, Computers \& Education, Vol 107, Pages: 164-147 